\title{
Environmental drivers of salp Thalia democratica population dynamics from in situ observations
}

\author{
Maria Pascual $^{1, *}$, Michael G. Neubert ${ }^{2}$, José Luis Acuña ${ }^{3}$, Andrew R. Solow ${ }^{2}$, Carlos \\ Dominguez-Carrió $^{1}$, Joaquín Salvador ${ }^{1}$, Alejandro Olariaga ${ }^{1}$, Verónica Fuentes ${ }^{1}$
}

\author{
${ }^{1}$ Institut de Ciències del Mar, 08003 Barcelona, Spain \\ ${ }^{2}$ Woods Hole Oceanographic Institution, Woods Hole, MA 02543, USA \\ ${ }^{3}$ Universidad de Oviedo, 33003 Oviedo, Spain
}

*Corresponding author: mpascual@icm.csic.es 
ABSTRACT: Thalia democratica blooms are a recurrent phenomenon in many coastal areas of the Mediterranean Sea and have significant ecological effects. To better understand the environmental drivers of salp blooms, we conducted 8 surveys to sample $T$. democratica in contrasting seasonal, temperature and chlorophyll conditions. In each survey, short-term variations in the abundances of different salp stages were assessed by sampling the same population at $30 \mathrm{~min}$ intervals. Using these data, we estimated the parameters in a set of stageclassified matrix population models representing different assumptions about the influence of temperature and chlorophyll on each stage. In the model that best explains our observations, only females are affected by changes in water temperature. Whether this is a direct influence of temperature or an indirect effect reflecting low food availability, female reproduction cessation seems to slow population growth under unfavourable conditions. When conditions become favourable again, females liberate the embryo and change sex to male, allowing for mating under extremely low salp densities and triggering the bloom. In contrast to previous findings, our results suggest that females, rather than oozooids, are responsible for the sustainability of salp populations during latency periods.

KEY WORDS: Matrix population models $\cdot$ Pelagic tunicate ecology $\cdot$ Population latency Gelatinous zooplankton blooms

\section{INTRODUCTION}

Salps are filter-feeding pelagic tunicates present in many of the world's seas. Salp blooms are common in most oceans and have important ecological consequences. They generate episodic but intense downward fluxes of faecal pellets and dead bodies (Lebrato et al. 2012, Henschke et al. 2013, Smith et al. 2014) and serve as prey and/or hosts for many pelagic and benthic organisms (Harbison 1998). Salp blooms can have important economic impacts as well, as high salp densities can (1) negatively impact fish farms (Giesecke et al. 2014), (2) clog the cooling systems of power plants and (3) potentially reduce tourism due to their jellyfish-like 
appearance (Boero et al. 2013). These adverse effects explain the growing interest in understanding the mechanisms that drive salp blooms.

Salp populations exhibit 'boom and bust' cycles due to the alternation between an asexual solitary stage (oozooid) and a sexual aggregated stage (blastozooid) during their life cycle (Fig. 1). Each blastozooid in a chain starts as a female and is impregnated almost immediately after its release. The female becomes male after giving birth to a single, freeswimming juvenile oozooid. Once the oozooid becomes sufficiently large, it becomes productive and sequentially releases up to 3 chains of blastozooids, closing the life cycle (Heron 1972a). The particularities of this cycle, combined with high individual growth rates (up to $28 \%$ in length per hour, Le Borgne \& Moll 1986), allow for very short generation times ( 2 d, Heron 1972b) and large intrinsic rates of population increase (Alldredge \& Madin 1982).

Salp blooms are population-level processes resulting from individual physiological responses to triggering environmental factors. Laboratory experiments have provided a wealth of information on how the growth, reproduction and survival rates of individual salps respond to environmental factors, usually temperature and food availability (e.g. Heron 1972a, Deibel 1982, Braconnot et al. 1988, Madin \& Purcell 1992). Those studies provide forcing functions which can be extrapolated to field conditions, allowing first-order approximations of population growth. However, laboratory measurements of physiological rates are highly variable and usually far from those derived from field studies (Heron \& Benham 1984, Madin \& Deibel 1998, Everett et al. 2011). In addition, the typical spatial and temporal scales of laboratory experiments preclude manipulation of whole salp populations. For these reasons, direct observation remains the best tool to study population-level phenomena, such as salp blooms (e.g. Heron, 1972a,b, Heron \& Benham 1984, 1985, Le Borgne \& Moll 1986, Tsuda \& Nemoto 1992, Loeb \& Santora 2012). In this regard, field observation has revealed associations between active salp population growth, low temperature and high food availability (Heron \& Benham 1985, Andersen \& Nival 
1986, Lavaniegos \& Ohman 2003, Licandro 2006, Deibel \& Paffenhöfer 2009, Henschke et al. 2014). Comparatively less attention has been given to population persistence during adverse conditions, when temperature is relatively high and food availability is low. Based on field observations, Heron \& Benham (1985) postulated that in latent, low-density populations of Thalia democratica, oozooids grow slowly, nursing chains of blastozooids that will release under favourable conditions.

Henschke et al. (2015) recently built a population dynamic model for $T$. democratica in which the vital rates were considered constant and based on published laboratory or field estimates. Since vital rates may vary with oceanographic conditions, the stage-classified model should include environment-dependent transition rates. In this regard, salp population models built by means of differential equations lend support to a role of chlorophyll and/or temperature levels as drivers of salp population dynamics (Andersen \& Nival 1986, Henschke et al. 2015).

The goal of the present study was to evaluate how $T$. democratica population dynamics change under different environmental conditions. For this purpose, we conducted short timeseries surveys around different $T$. democratica blooms under contrasting environmental conditions and used these observations to fit temperature- and chlorophyll-dependent stageclassified matrix models. Our main findings are in contrast to previous hypotheses (Heron \& Benham 1985) that pointed to the asexual stage as being responsible for population latency: we propose that females limit their reproduction when conditions turn unfavourable, thus lowering the population growth rate. When favourable conditions resume, females liberate their embryo and become males, allowing for mating at low salp densities and triggering a bloom.

\section{MATERIALS AND METHODS}

\section{Sampling area}


All sampling stations were located in the Catalan Sea, NW Mediterranean. The most relevant hydrographical structure in this area is the density front produced by differences in salinity between coastal and oceanic waters. Associated with this shelf-slope front, a current flowing southward is formed (Font et al. 1988). Catalan coastal waters can be considered oligotrophic, although substantial nutrient sources, mostly coming from river runoff, turn them into a more productive area than the open sea (Arin et al. 2013, Saiz et al. 2014). Primary production in the NW Mediterranean exhibits a strong seasonality, mainly forced by changes in surface temperature (Duarte et al. 1999). During autumn and winter, stronger and colder winds cool down the superficial waters, inducing vertical mixing of the water column, which in turn enriches the euphotic layer with nutrients. In late winter and early spring, water starts to warm and the stability of the water column increases rapidly, triggering a rise in primary production. The pronounced warming and stratification in summer causes a depletion of nutrients in the euphotic layer, which decreases phytoplankton growth. Finally, the thermocline starts to break again in autumn and a second, but less intense, phytoplankton bloom occurs (Ménard et al. 1994, Estrada 1996).

Two locations (both approximately $1.6 \mathrm{~km}$ from shore) were selected for the different surveys. The first sampling site, Cadaqués $\left(42^{\circ} 18^{\prime} 34.5^{\prime}\right.$ N, $3^{\circ} 19^{\prime} 19.3$ ” E; bottom depth $=60$ $\mathrm{m})$, is located in front of the Cap de Creus area, an area where the continental shelf is particularly narrow and oceanic waters exert a strong influence. In contrast, the second sampling site, Barcelona $\left(41^{\circ} 20.844^{\prime} \mathrm{N}, 2^{\circ} 17.888^{\prime} \mathrm{E}\right.$; bottom depth $\left.=40 \mathrm{~m}\right)$, is located in an area with a wider continental shelf, where the shelf-slope front is relatively far from shore (Fig. 2). Two main rivers have an influence on the nutrient concentrations: the Rhône River in the case of Cadaqués, with maximum flows in autumn and spring (Ulses et al. 2008), and the Besós River in the case of Barcelona, with discharge peaks in autumn and winter (Arin et al. 2013). Sampling positions and depths may have varied slightly since a drifting buoy was followed during sampling. 


\section{Sample collection}

Monthly time series

To determine the pattern of temporal variation of Thalia democratica populations, we conducted time-series surveys in both locations where monthly samples were collected during 2013 and 2014. Temperature and salinity profiles were obtained by deploying a CTD down to 20 m depth. Chlorophyll $a$ ( $\operatorname{chl} a$ ) concentrations were measured in water samples collected $1 \mathrm{~m}$ below the sea surface using a 51 Niskin bottle. Zooplankton samples were collected using a bongo net (40 cm diameter, $300 \mu \mathrm{m}$ mesh size), obliquely towed for $10 \mathrm{~min}$ from $10 \mathrm{~m}$ depth to the surface. Sampling deeper layers or at certain times of the day was unnecessary, as $T$. democratica is considered a non-migrant species and mainly occurs in surface waters (Heron 1972b, Tsuda \& Nemoto 1992, Paffenhöfer et al. 1995). Samples were preserved in 5\% formalin immediately after being collected.

Short time-series observations

When salps were easily recognizable in the first zooplankton sample of each monthly visit, we followed a short time-series sampling methodology. From that point until the end of the bloom, we increased the sampling frequency, provided that weather conditions allowed. Following Heron (1972b), each survey comprised 6 consecutive hauls, performed at 30 min intervals, tracking a World Ocean Circulation Experiment (WOCE) drifting buoy (Hansen \& Poulain 1996). Each haul started near the buoy that followed surface waters, thus tracking the salp population. If salp density was high enough to collapse the bongo net cod ends, towing time was reduced to $5 \mathrm{~min}$. CTD and Niskin bottles were deployed near the drifting buoy after plankton samples were collected, as was also the case for the monthly surveys (i.e. 3 to $4 \mathrm{~h}$ after sampling had begun). Both samplings were conducted during daylight, avoiding dusk and dawn since these periods can affect salp distributions due to mating aggregations (Gibbons 1997). We 
assumed no net-avoidance by the salps given their slow swimming response (Ohman \& Lavaniegos 2002).

\section{Sample analyses}

Salps efficiently retain particles above 2 to $3 \mu \mathrm{m}$ in size (Kremer \& Madin 1992, but see Sutherland et al. 2010). To obtain an estimation of the concentration of phytoplankton available to salps, water samples were size-fractionated through $3 \mu \mathrm{m}$ Whatman polycarbonate filters and glass fibre GF/F filters $(0.45 \mu \mathrm{m})$. Chl $a$ was extracted from those filters for $24 \mathrm{~h}$ at $4^{\circ} \mathrm{C}$ using 90\% acetone (Venrick \& Hayward 1984). Fluorescence of the acetone solution was measured using a fluorometer (Turner Designs). We only considered total chl $a$ concentrations, since total chl $a$ rendered a better model fit and both size fractions were highly correlated (Spearman's coefficients $>0.7$ ). A better fit of population parameters with the smallest fraction agrees with the capacity of salps to retain sub-micrometre particles (Sutherland et al. 2010).

T. democratica individuals were identified, separated from the original sample and then scanned using a Zooscan (Grosjean et al. 2004). Individuals were measured from the posterior ridge of the gut to the opening (Foxton 1966) using Image J software (Abramoff et al. 2004), measuring up to a maximum of 1000 individuals each of blastozooids and oozooids. The number of buds chain ${ }^{-1}$ was also counted (up to a maximum of 50 oozooids survey ${ }^{-1}$ ) only when the oldest chain was clearly distinguishable from the stolon (Henschke et al. 2014). These values were then used to determine the maximum and minimum number of buds chain ${ }^{-1}$ in the models.

Individuals were classified in 4 stages depending on the blastozooid/oozooid form and size as described by Henschke et al. (2015), after applying a 10\% shrinkage correction due to the effects of formalin (Heron et al. 1988). Samples from all surveys were measured during the first month after collection. Size ranges were adjusted to our observations, adapting previous partitions to actual data from the population sampled. For example, the maximum length 
measured for a blastozooid carrying an embryo was $7 \mathrm{~mm}$, and oozooids containing a developed chain reached lengths of $8 \mathrm{~mm}$. These measures are similar to those found in other studies on $T$. democratica in the Mediterranean Sea (e.g. Braconnot \& Jegu 1981). Therefore, we classified individuals as female ( $\mathrm{F}$, blastozooid, size range: 1-7 mm), male (M, blastozooid, size range: $>7$ $\mathrm{mm}$ ), juvenile oozooid (J, oozooid, size range: $3-8 \mathrm{~mm}$ ) and productive oozooid (PO, oozooid, size range $>8 \mathrm{~mm}$ ). The density of individuals (ind. $100 \mathrm{~m}^{-3}$ ) in each stage was calculated by dividing the number of individuals by the total volume of water filtered. When blastozooids or oozooids exceeded 1000 individuals, we multiplied their relative size frequencies by the total density of individuals to obtain the stage density. One individual count was added to all samples prior to calculation of densities to avoid logarithms of 0 in the parameter estimation procedure.

\section{Model construction and parameter estimation}

We modelled the population dynamics of $T$. democratica using a stage-classified matrix model based on the life cycle as represented in Fig. 1. First, we classified all individuals in the population at time $t$ as either female $\left(F_{t}\right)$, male $\left(M_{t}\right)$, juvenile oozooid $\left(J_{t}\right)$ or reproductive oozooid $\left(\mathrm{PO}_{t}\right)$, and gathered the counts of the classified individuals into a vector representing the population stage distribution at time $t$. The model projects the stage distribution from time $t$ to time $t+1$ via matrix multiplication:

$$
\left[\begin{array}{c}
F_{t+1} \\
M_{t+1} \\
J_{t+1} \\
P O_{t+1}
\end{array}\right]=\left[\begin{array}{cccc}
P_{\mathrm{F}} & 0 & R_{\mathrm{J}} & R_{\mathrm{PO}} \\
G_{\mathrm{F}} & P_{\mathrm{M}} & 0 & 0 \\
R_{\mathrm{F}} & 0 & P_{\mathrm{J}} & 0 \\
0 & 0 & G_{\mathrm{J}} & P_{\mathrm{PO}}
\end{array}\right]\left[\begin{array}{c}
F_{t} \\
M_{t} \\
J_{t} \\
P O_{t}
\end{array}\right]
$$

The entries in this matrix correspond to the rates of the transitions illustrated in Fig. 1. $P_{\mathrm{M}}$ and $P_{\mathrm{PO}}$ are the survival rates for males and productive oozooids. Females at time $t$ either survive and remain female (with probability $P_{\mathrm{F}}$ ), or grow and become male (with probability $G_{\mathrm{F}}$ ), or die. Since a female sheds a juvenile oozooid and becomes a male simultaneously, the probability to release the embryo is $R_{\mathrm{F}}=G_{\mathrm{F}} . P_{\mathrm{J}}$ and $G_{\mathrm{J}}$ are the probability that an oozooid remains a juvenile 
and the probability that it grows to become a productive oozooid, respectively. $R_{\mathrm{J}}$ and $R_{\mathrm{PO}}$ give the rate of production of new females by juvenile and productive oozooids. We assumed that reproduction is a birth-flow process sensu Caswell (2001).

In general, each of these transitions, and so each of the positive elements of the transition matrix, may depend on temperature $(T)$ or chlorophyll concentration $(c h l)$, or both. We incorporate these potential environmental effects through the parametric models listed in Table 1. Each parametric model is a logistic or multinomial logistic function, since each element in the transition matrix is the probability of an event to happen among 2 or more alternatives (i.e. dichotomous or polytomous data). For example, $P_{\mathrm{M}}$ represents the male survival probability to the following time step. Thus, it consists of 2 potential alternatives (to survive or not) and is accordingly modelled by a binomial logistic function. In contrast, $P_{\mathrm{F}}$ represents the probability of an event-remaining female — among a set of 3 different possibilities: to die, to remain in the same state or to grow and become a male. Accordingly, a multinomial logistic function was used. Note that $G_{\mathrm{F}}$ represents the probability of a different event-to grow to male-among exactly the same set of possibilities as in $P_{\mathrm{F}}$. Blastozooid production $\left(R_{\mathrm{PO}}\right.$ and $\left.R_{\mathrm{J}}\right)$ includes a mean oozooid fecundity term $(\bar{f})$ and a mean newborn blastozooid survival term $(\bar{S})$ within the same time interval, since oozooids produce chains continuously. To comport with our observations, the minimum $\left(f_{\min }\right)$ and maximum $\left(f_{\max }\right)$ number of blastozoids per oozooid were constrained between 14 ( 1 chain with only 14 blastozooids) and 258 ( 3 chains with up to 68 blastozooids each).

The general model (Eq. 1) involves a total of 25 parameters. Different restrictions on these parameters correspond to different hypotheses about the role of temperature and chlorophyll in the population dynamics of different life stages of $T$. democratica (see life cycle illustrated in Fig. 1). To select among these hypotheses, we fit a total of 48 models. These models correspond to combinations of temperature-dependence only, chlorophyll-dependence 
only and both temperature- and chlorophyll-dependence operating on all 16 possible combinations of life stages (Table 2).

To estimate the parameters in this model, we must incorporate stochasticity to account for variability in the data. Dennis et al. (1995) described the statistical advantages of adding noise on the log scale. Doing so transforms Eq. (1) to:

$$
\left[\begin{array}{c}
F_{t+1} \\
M_{t+1} \\
J_{t+1} \\
P O_{t+1}
\end{array}\right]=\left[\begin{array}{cccc}
\mathrm{e}^{E_{\mathrm{F}}} & 0 & 0 & 0 \\
0 & \mathrm{e}^{E_{\mathrm{M}}} & 0 & 0 \\
0 & 0 & \mathrm{e}^{E_{\mathrm{J}}} & 0 \\
0 & 0 & 0 & \mathrm{e}^{E_{\mathrm{PO}}}
\end{array}\right]\left[\begin{array}{cccc}
P_{\mathrm{F}} & 0 & R_{\mathrm{J}} & R_{\mathrm{PO}} \\
G_{\mathrm{F}} & P_{\mathrm{M}} & 0 & 0 \\
R_{\mathrm{F}} & 0 & P_{\mathrm{J}} & 0 \\
0 & 0 & G_{\mathrm{J}} & P_{\mathrm{PO}}
\end{array}\right]\left[\begin{array}{c}
F_{t} \\
M_{t} \\
J_{t} \\
P O_{t}
\end{array}\right]
$$

where the vector $\left[\begin{array}{llll}E_{\mathrm{F}} & E_{\mathrm{M}} & E_{\mathrm{J}} & E_{\mathrm{PO}}\end{array}\right]^{\mathrm{T}}$ has a multivariate normal distribution with 0 mean and variance-covariance matrix $\boldsymbol{\Sigma}$. On the log scale we then have

$$
\begin{aligned}
& \ln \left(F_{t+1}\right)=\ln \left(P_{\mathrm{F}} F_{t}+R_{\mathrm{J}} J_{t}+R_{\mathrm{PO}} P O_{t}\right)+E_{\mathrm{F}} \\
& \ln \left(M_{t+1}\right)=\ln \left(G_{\mathrm{F}} F_{t}+P_{\mathrm{M}} M_{t}\right)+E_{\mathrm{M}} \\
& \ln \left(J_{t+1}\right)=\ln \left(R_{\mathrm{F}} F_{t}+P_{\mathrm{J}} J_{t}\right)+E_{\mathrm{J}} \\
& \ln \left(P O_{t+1}\right)=\ln \left(G_{\mathrm{J}} J_{t}+P_{\mathrm{PO}} P O_{t}\right)+E_{\mathrm{PO}}
\end{aligned}
$$

We fit the models described by Eqs. (3-6) and Table 2 by nonlinear least squares. We compared models using the cross-validated 1-step prediction errors of the log-transformed population counts. Cross-validation is commonly used in comparing models, like those in Table 2, that differ in the number of fitted parameters (Claeskens \& Hjort 2008). Otherwise, using noncross-validated sum of squared prediction errors would tend to favour models with more parameters. We then used the selected model to estimate the transition matrix, the population growth rate $(\lambda)$ and the elasticity matrix for selected environmental conditions. We constructed approximate 0.95 confidence intervals for the fitted values of the stage counts conditional on the initial counts by the percentile bootstrap method based on 200 bootstrap samples of the residuals from the fitted model (Efron $\&$ Tibshirani 1993). $\lambda$ was calculated as the first eigenvalue of the 
transition matrix, and reflects the long-term behaviour of the population under constant conditions. The population decreases exponentially when $0<\lambda<1$ and increases when $\lambda>1$. The elasticity of $\lambda$ with respect to one of the matrix elements indicates the proportional contribution of this matrix element to $\lambda$, and was computed following standard methods (Caswell 2001).

\section{RESULTS}

The temperature range in Barcelona was wider than in Cadaqués $\left(12.2-24.9^{\circ} \mathrm{C}\right.$ vs. $11.6-$ $23.7^{\circ} \mathrm{C}$ ), while total chl $a$ concentrations were slightly lower in Barcelona (0.07-1.03 vs. 0.07$1.25 \mu \mathrm{g} \mathrm{l^{-1 }}$; Fig. 3). Since environmental conditions can be considered relatively similar, both locations were treated as survey replicates. Thalia democratica appeared from May to June/July, and between September and October in 2013 and 2014 (Fig. 3). Abundances in Cadaqués during spring time were higher than those recorded in Barcelona or during autumn. T. democratica was the only salp forming blooms in all sampling events except for spring 2013, when Salpa fusiformis was also present at both locations (Fig. 3). When salp abundance was low (1 ind. 100 $\mathrm{m}^{-3}$ or less), populations were mostly composed of blastozooids.

Salp densities and meteorological conditions favoured the development of 8 short timeseries observations (marked with asterisks in Fig. 3; see size distributions in Fig. S1 in the Supplementary material) each covering 5 time transitions $(0-0.5,0.5-1.0,1.0-1.5,1.5-2.0$ and 2.0-2.5 h). The total number of time transitions was 40 (i.e. 5 time transitions in each of the 8 surveys), all of which were used to fit the models. The model that best explained the variability observed in our data included only females affected by temperature (Table 2). This effect can be estimated using the model equations from Table 3. Accordingly, the probability of females growing to males $\left(G_{\mathrm{F}}\right)$ and the concomitant probability of releasing an embryo $\left(R_{\mathrm{F}}\right)$ decreased with increasing temperature (Fig. 4a). In contrast, the probability of remaining a female $\left(P_{\mathrm{F}}\right)$ was 
higher in warmer waters. Within the temperature range of this study $\left(14-22^{\circ} \mathrm{C}\right), G_{\mathrm{F}}$ varied between 0.1 and $7.6 \%$ for a 30 min time step. The number of buds per oozooid per 30 min time step was inversely correlated to temperature and ranged from 31 to 52. Population growth rate ( $\lambda$ ) smoothly decreased with temperature from 0.946 to 0.784 . Elasticities (proportional sensitivity of $\lambda$ to variation in a particular matrix element) also varied with temperature. Values were more balanced at low temperatures, with slightly higher elasticities for $P_{\mathrm{PO}}$ (Fig. $\left.4 \mathrm{~b}\right)$. In contrast, elasticity values for $P_{\mathrm{F}}$ were clearly higher at high temperatures.

For the sake of comparison with existing literature, it is possible to derive the stagedependent survival rates from our model probabilities to remain in the same stage $(P)$ and to grow until the next stage $(G)$, following the methods given by Caswell (2001). An individual will remain in the same stage $(P)$ if it survives $(s)$ and does not grow $(1-g)$, thus $P=s \times(1-g)$. $(G)$ if it survives and grow ( $g$ ), that is, $G=s \times g$. By using $P$ and $G$ estimates from the best model, we could calculate survival rates $(s)$ by solving a 2-equation system. Survival values of each stage are shown in Table 4. Note that $g$ is the probability of growing to the next stage and not an individual increase in length; thus, these values are not comparable with growth rates reported in previous studies.

\section{DISCUSSION}

We have explored the population dynamics of the salp Thalia democratica by combining a stage-specific matrix model with empirical modelling of the transition matrix elements. Our study highlights the key role of the female stage during periods of population latency, a conclusion that departs from previous hypotheses (Heron \& Benham 1985). Our approach required samples of relatively dense salp populations (at least 60 ind. $100 \mathrm{~m}^{-3}$ ) to achieve meaningful parameter estimates. This method, however, does not need well-defined size distributions since it is not based on identified cohort peak displacements, which would require greater abundances (Heron 1972a). T. democratica populations in the NW Mediterranean reach 
abundances up to 11000 ind. $100 \mathrm{~m}^{-3}$ (Licandro 2006), much denser than those found in the present study (Fig. 3). There is the possibility that the highest salp densities may have been missed by the coarse, monthly sampling frequency of our study. However, maximal annual abundances reported by Licandro (2006) from 1974 to 1999 varied among years, mostly from 10 to 1000 ind. $100 \mathrm{~m}^{-3}$, and densities greater than 1000 ind. $100 \mathrm{~m}^{-3}$ were only recorded in a few occasions. We sampled only blooms, because salp abundance during non-bloom periods ranges from 0 to $<10$ ind. $100 \mathrm{~m}^{-3}$ (Fig. 3) (Sardou et al. 1996), which is our approximate operational threshold. It can be assumed that population growth rates < 1 suggest that our observed, dense populations might have been entering senescence. However, if population growth rates were $>1$, we would still expect a similar effect of temperature on population growth. Bearing in mind these experimental limitations, our 1-time-step expected densities fitted reasonably well with our observations (Fig. 5), and the estimated stage-dependent survival rates were in consonance with those obtained from previous model-derived rates (e.g. Henschke et al. 2015; Table 4).

\section{Effect of temperature on salp dynamics}

The range of temperatures recorded was sufficient to evaluate its effects on salp dynamics. The model that best explained the variability observed in the population dynamics of T. democratica pointed to a direct, negative effect of temperature on females. Low temperatures were associated with favourable conditions for salps, while high temperatures corresponded to periods of salp population arrest (Fig. 4). Although the effects of temperature seemed clear, these results can be attributed to either direct influence on salp physiology or an indirect, seasonal correlation with primary production. Temperatures above $20^{\circ} \mathrm{C}$ negatively affect feeding rates in Salpa fusiformis (Andersen 1986), and greater excretion rates in warmer waters could have been detrimental for the salp population (Ménard et al. 1994). On the other hand, temperature has traditionally been inversely related to primary production in the Mediterranean Sea (Bosc et al. 2004, Saiz et al. 2014). Both spring and autumn phytoplankton peaks normally preceded a salp 
bloom (Ménard et al. 1994), but salps in autumn (high temperature) would have less food available than in spring (low temperature). We have not seen salp blooms in winter, coinciding with the lowest water temperature registered, probably because thermocline formation and the rise of primary production have not yet started (Fig. 3).

Our results agree with other studies that found a negative correlation between temperature and salp abundance (Ménard et al. 1994, Licandro 2006). In addition to high temperatures, water column stability and irradiance may contribute to the termination of salp blooms (Ménard et al. 1994). Nevertheless, all of these factors seem to be associated with the annual cycle of the water column in the NW Mediterranean. Our study contrasts with others in which chl $a$, a measure of food availability, was correlated with salp population dynamics (Heron \& Benham 1984, Andersen \& Nival 1986, Deibel \& Paffenhöfer 2009, Henschke et al. 2014). The chl $a$ range used in our study may have been too narrow, or alternatively there may be a lagged response of salp populations to food availability (Licandro 2006). It is possible that primary production would describe food availability better than chl $a$, but the methodology needed to obtain these values was logistically impossible in our study.

\section{Stages contributing to population growth under contrasting conditions}

Elasticity analysis has shown that the survival of oozooids stimulated population growth during cold, favourable periods (Fig. 4b). These results are in agreement with other studies pointing to oozooid survival as the most sensitive vital parameter of the population dynamics (Henschke et al. 2015), as well as asexual reproduction, a key parameter for exponential growth (Alldredge \& Madin 1982, Andersen \& Nival 1986). Under unfavourable conditions (high temperature and low food availability), females invest their low energy input into slow growth while arresting reproduction, leading to slow population growth (Fig. 4b). In this sense, we observed that low-density populations $\left(\leq 1\right.$ ind. $\left.100^{-3}\right)$ were exclusively dominated by blastozooids, indicating the potential role of females as a switch for population growth. The 
decrease in female reproduction also fits our size distributions, where surveys with high temperatures $\left(>19^{\circ} \mathrm{C}\right)$ had no males, indicating that females were not reproducing (see Fig. $\mathrm{S} 1 \mathrm{~g}-\mathrm{j}$ in the Supplement). These findings are in agreement with other studies that found populations mostly dominated by females in autumn and winter samples (Heron \& Benham 1985, Tew \& Lo 2005). Interestingly Heron \& Benham (1985) also observed that blastozooids were not reproducing, although they concluded that, in the typical situation for population latency (what they called 'overwintering'), oozooids arrested their growth while retaining their chains until the onset of favourable conditions.

In our study, the probability of remaining in the same stage $(P)$ exhibited higher elasticities than reproductive rates $(R)$ (Fig. $4 \mathrm{~b}$ ). In other words, shortening or enlarging the residence time in a given stage has more influence on population dynamics than producing more or less offspring (Heron 1972b). T. democratica could control its population increase rates $(r)$ through time, rather than clutch manipulation (sensu Aksnes \& Giske 1990), as other pelagic tunicates like the appendicularian Oikopleura dioica would do (Subramaniam et al. 2014; but see Troedsson et al. 2002).

\section{Importance of females in salp dynamics}

In contrast to hypotheses centred on the role of the oozooid stages (Heron \& Benham 1985), our results suggest that $T$. democratica females unfold a clockwork sequence of processes that initiates the bloom (Fig. 1). Once conditions improve, the female liberates an oozooid when still physically close to its daughters and becomes a male. This situation would favour sex encounters in conditions of extreme population dilution. In this sense, we assume that (1) the embryo is nearly mature when released (i.e. carrying a primordial chain of daughter females) (Alldredge \& Madin 1982, Miller \& Cosson 1997); (2) testes develop when blastozooids are still nursing the embryo and become mature after giving birth (Madin \& Purcell 1992); and (3) there is a partial overlap between the time in which oozooids start liberating chains, males release the 
sperm and females liberate the embryos (Miller \& Cosson 1997). In an isolated group of closely related individuals, a sex ratio extremely skewed towards females (i.e. 1 male, many daughters) should maximize fitness (Hamilton 1967). If true, this mechanism would imply inbreeding during the early stages of a bloom, a process that could be detected using genetic markers. It should also increase fertilization success among males and daughters. These testable predictions may set the basis for future studies on salp dynamics.

\section{CONCLUSIONS}

We used an inverse method combining a stage-classified matrix population model, combined with empirical in situ observations, to understand how the vital rates of Thalia democratica vary with changing environmental conditions. Our results point to females, not the asexual oozooid as previously hypothesized, as the key stage to sustaining the population under the latency period. Productive oozooid survival accounted for high population growth under favourable conditions, while growth arrest in females lowered population growth under unfavourable conditions. In both scenarios, salps control population growth by time rather than by clutch manipulation. After a latency period, females tend to release the oozooids, which are already generating chains of females, and then become male. Therefore, we postulate that females may be the triggering mechanism to end the latency periods and initiate the salp bloom. This is the first study that has attempted to analyse how the processes inside the population vary in a changing environment. Understanding the latency period is essential, since it sustains the population under unfavourable environments, allowing the occurrence of new blooms.

Acknowledgements. This work was founded by the Ministerio de Ciencia e Innovación under the Fishjelly project, the European commission ENPI CBC MED project under the Jellyrisk project and the European LIFE Commission under the Cubomed project. M. G. Neubert acknowledges 
the support of the US National Science Foundation (DEB-1145017 and DEB-1257545). We thank Vicente Llinares, Jordi Carol, Raül González and Marco Leone for their assistance with the field work and sample analysis. We also thank Julio Arrontes, Larry Madin and Hal Caswell for their expert advice. This study is a contribution of the Marine Zooplankton Ecology Group (2014SGR-498) at the Institut de Ciències del Mar-CSIC.

\section{LITERATURE CITED}

Abramoff MD, Magalhaes PJ, Ram SJ (2004) Image processing with Image J. Biophoton Int 11:3642

Aksnes DL, Giske J (1990) Habitat profitability in pelagic environments. Mar Ecol Prog Ser 64:209-215 doi:10.3354/meps064209

Alldredge AL, Madin LP (1982) Pelagic tunicates: unique herbivores in the marine plankton. Bioscience 32:655-663 doi:10.2307/1308815

Andersen V (1986) Effect of temperature on the filtration rate and percentage of assimilation of Salpa fusiformis Cuvier (Tunicata: Thaliacea). Hydrobiologia 137:135-140

Andersen V, Nival P (1986) A model of the population dynamics of salps in coastal waters of the Ligurian Sea. J Plankton Res 8:1091-1110 doi:10.1093/plankt/8.6.1091

Arin L, Guillén J, Segura-Noguera M, Estrada M (2013) Open sea hydrographic forcing of nutrient and phytoplankton dynamics in a Mediterranean coastal ecosystem. Estuar Coast Shelf Sci 133:116-128 doi:10.1016/j.ecss.2013.08.018

Boero F, Belmonte G, Bracale R, Fraschetti S, Piraino S, Zampardi S (2013) A salp bloom (Tunicata, Thaliacea) along the Apulian coast and in the Otranto Channel between March-May 2013. F1000Res 2:181 PubMed

Bosc E, Bricaud E, Antoine D (2004) Seasonal and interannual variability in algal biomass and 
primary production in the Mediterranean Sea, as derived from 4 years of SeaWiFS observations. Global Biogeochem Cycles 18:GB1005 doi:10.1029/2003GB002034

Braconnot JC, Jegu M (1981) Le cycle de Thalia democratica (Salpidae). Croissance et durée de chaque génération. Rapp P-v Réun Comm Int Explor Sci Mer Médit 27:197-198

Braconnot JC, Choe SM, Nival P (1988) La croissance et le développement de Salpa fusiformis Cuvier (Tunicata, Thaliacea). Ann Inst Océanogr 64:101-114

Caswell H (2001) Matrix population models: construction, analysis, and interpretation, 2nd edn. Sinauer Associates, Sunderland, MA

Claeskens G, Hjort NL (2008) Model selection and model averaging. Cambridge University Press, Cambridge

Deibel D (1982) Laboratory determined mortality, fecundity and growth rates of Thalia democratica Forskal and Dolioletta gegenbauri Uljanin (Tunicata, Thaliacea). J Plankton Res 4:143-153 doi:10.1093/plankt/4.1.143

Deibel D, Paffenhöfer GA (2009) Predictability of patches of neritic salps and doliolids (Tunicata, Thaliacea). J Plankton Res 31:1571-1579 doi:10.1093/plankt/fbp091

Dennis B, Desharnais RA, Cushing JM, Costantino RF (1995) Nonlinear demographic dynamics: mathematical models, statistical methods, and biological experiments. Ecol Monogr 65:261-281 doi: $10.2307 / 2937060$

Duarte CM, Agustí S, Kennedy H, Vaqué D (1999) The Mediterranean climate as a template for Mediterranean marine ecosystems: the example of the northeast Spanish littoral. Prog Oceanogr 44:245-270 doi:10.1016/S0079-6611(99)00028-2

Duggins DO (1981) Sea urchins and kelp: the effects of short term changes in urchin diet. Limnol Oceanogr 26:391-394 doi:10.4319/1o.1981.26.2.0391 
Efron B, Tibshirani RJ (1993) An introduction to the bootstrap. Monographs on Statistics and Applied Probability 57. Springer Science+Business Media, Dordrecht

Estrada M (1996) Primary production in the northwestern Mediterranean. Sci Mar 60:55-64

Everett JD, Baird ME, Suthers IM (2011) Three-dimensional structure of a swarm of the salp Thalia democratica within a cold-core eddy off southeast Australia. J Geophys Res 116:C12046 doi:10.1029/2011JC007310

Font J, Salat J, Tintoré J (1988) Permanent features of the circulation in the Catalan Sea. Oceanol Acta 9(Spec Issue):51-57

Fortier L, Le Fèvre J, Legendre L (1994) Export of biogenic carbon to fish and to the deep ocean: the role of large planktonic microphages. J Plankton Res 16:809-839 doi:10.1093/plankt/16.7.809</jrn>

Foxton P (1966) The distribution and life-history of Salpa thompsoni Foxton with observations on a related species, Salpa gerlachei Foxton. Discov Rep 24:1-116

Gibbons MJ (1997) Vertical distribution and feeding of Thalia democratica on the Agulhas Bank during march 1994. J Mar Biol Assoc UK 77:493-505 doi:10.1017/S0025315400071824

Giesecke A, Garcés-Vargas J, Mardones J, González HE, Caputo L, Castro L (2014) Massive salp outbreaks in the inner sea of Chiloé Island (Southern Chile): possible causes and ecological consequences. Lat Am J Aquat Res 42:604-621 doi:10.3856/vol42-issue3-fulltext-18

Grosjean P, Picheral M, Warembourg C, Gorsky G (2004) Enumeration, measurement, and identification of net zooplankton samples using the ZOOSCAN digital imaging system. ICES J Mar Sci 61:518-525 doi:10.1016/j.icesjms.2004.03.012

Hamilton WD (1967) Extraordinary sex ratios. Science 156:477-488 PubMed doi:10.1126/science.156.3774.477 
Hansen DV, Poulain PM (1996) Quality control and interpolations of WOCE-TOGA drifter data. J Atmos Ocean Technol 13:900-909 doi:10.1175/15200426(1996)013<0900:QCAIOW>2.0.CO;2

Harbison GR (1998) The parasites and predators of Thaliacea. In: Bone Q (ed) The biology of pelagic tunicates. Oxford University Press, Plymouth, p 187-214

Henschke N, Bowden DA, Everett JD, Holmes SP, Kloser RJ, Lee RW, Suthers IM (2013) Salp-falls in the Tasman Sea: a major food input to deep-sea benthos. Mar Ecol Prog Ser 491:165-175 doi:10.3354/meps 10450

Henschke N, Everett JD, Doblin MA, Pitt KA, Richardson AJ, Suthers IM (2014) Demography and interannual variability of salp swarms (Thalia democratica). Mar Biol 161:149-163 doi:10.1007/s00227-013-2325-2

Henschke N, Smith JA, Everett JD, Suthers IM (2015) Population drivers of a Thalia democratica swarm: insights from population modelling. J Plankton Res 37:1074-1087

Heron AC (1972a) Population ecology of colonizing species: the pelagic tunicate Thalia democratica. I. Individual growth rate and generation time. Oecologia 10:269-293 doi:10.1007/BF00345733

Heron AC (1972b) Population ecology of a colonizing species: the pelagic tunicate Thalia democratica. II. Population growth rate. Oecologia 10:294-312 doi:10.1007/BF00345734

Heron AC, Benham EE (1984) Individual growth rates of salps in three populations. J Plankton Res 6:811-828 doi:10.1093/plankt/6.5.811

Heron AC, Benham EE (1985) Life history parameters as indicators of growth rate in three salp populations. J Plankton Res 7:365-379 doi:10.1093/plankt/7.3.365

Heron AC, McWilliam PS, Dal Pont G (1988) Length-weight relation in the salp Thalia 
democratica and potential of salps as a source of food. Mar Ecol Prog Ser 42:125-132 doi:10.3354/meps042125

Kremer P, Madin L (1992) Particle retention efficiency of salps. J Plankton Res 14:1009-1015 doi:10.1093/plankt/14.7.1009

Lavaniegos BE, Ohman MD (2003) Long-term changes in pelagic tunicates of the California Current. Deep-Sea Res II 50:2473-2498 doi:10.1016/S0967-0645(03)00132-2

Le Borgne R, Moll P (1986) Growth rates of the salp Thalia democratica in Tikehau atoll (Tuamoto is.). Oceanogr Trop 21:23-29</jrn>

Lebrato M, Pitt KA, Sweetman AK, Jones DOB and others (2012) Jelly-falls historic and recent observations: a review to drive future research directions. Hydrobiologia 690:227-245 doi:10.1007/s10750-012-1046-8

Licandro P (2006) Long-term fluctuations (1974-1999) of the salps Thalia democratica and Salpa fusiformis in the northwestern Mediterranean Sea : relationships with hydroclimatic variability. Limnol Oceanogr 51:1832-1848 doi:10.4319/lo.2006.51.4.1832

Loeb VJ, Santora JA (2012) Population dynamics of Salpa thompsoni near the Antarctic Peninsula: growth rates and interannual variations in reproductive activity (1993-2009). Prog Oceanogr 96:93-107 doi:10.1016/j.pocean.2011.11.001

Madin LP, Deibel D (1998) Feeding and energetics of Thaliacea. In: Bone Q (ed) The biology of pelagic tunicates. Oxford University Press, Plymouth, p 81-103

Madin LP, Purcell JE (1992) Feeding, metabolism and growth of Cyclosalpa bakeri in the subarctic Pacific. Limnol Oceanogr 37:1236-1251 doi:10.4319/lo.1992.37.6.1236

Ménard F, Dallot S, Thomas G, Braconnot JC (1994) Temporal fluctuations of two Mediterranean salp populations from 1967 to 1990 . Analysis of the influence of environmental variables using a 
Markov chain model. Mar Ecol Prog Ser 104:139-152 doi:10.3354/meps104139

Miller RL, Cosson J (1997) Timing of sperm shedding and release of aggregates in the salp Thalia democratica (Urochordata: Thaliacea). Mar Biol 129:607-614 doi:10.1007/s002270050203

Ohman MD, Lavaniegos BE (2002) Comparative zooplankton sampling efficiency of a ring net and bongo net with comments on pooling of subsamples. Calif Coop Ocean Fish Invest Rep 43:162173

Paffenhöfer GA, Atkinson LP, Lee TN, Verity PG, Bulluck LR (1995) Distribution and abundance of thaliaceans and copepods off the southeastern USA during winter. Cont Shelf Res 15:255-280 doi:10.1016/0278-4343(94)E0004-6

Perissinotto R, Pakhomov EA (1998) Contribution of salps to carbon flux of marginal ice zone of the Lazarev Sea, southern ocean. Mar Biol 131:25-32 doi:10.1007/s002270050292

Saiz E, Sabatés A, Gili JM (2014) The zooplankton. In: Goffredo S, Dubinsky Z (eds) The Mediterranean Sea: its history and present challenges. Springer Science+Business Media, Dordrecht, p 183-211

Sardou J, Etienne M, Andersen V (1996) Seasonal abundance and vertical distributions of macroplankton and micronekton of the Northwestern Mediterranean Sea. Oceanol Acta 19: 645656

Smith KL, Sherman AD, Huffard CL, McGill PR and others (2014) Large salp bloom export from the upper ocean and benthic community response in the abyssal northeast Pacific: day to week resolution. Limnol Oceanogr 59:745-757 doi:10.4319/lo.2014.59.3.0745

Subramaniam G, Campsteijn C, Thompson EM (2014) Lifespan extension in a semelparous chordate occurs via developmental growth arrest just prior to meiotic entry. PLOS ONE 9:e93787 PubMed doi:10.1371/journal.pone.0093787 
Sutherland KR, Madin LP, Stocker R (2010) Filtration of submicrometer particles by pelagic tunicates. Proc Natl Acad Sci USA 107:15129-15134 PubMed doi:10.1073/pnas.1003599107

Tew KS, Lo WT (2005) Distribution of Thaliacea in SW Taiwan coastal water in 1997, with special reference to Doliolum denticulatum, Thalia democratica and T. orientalis. Mar Ecol Prog Ser 292:181-193 doi:10.3354/meps292181

Troedsson C, Bouquet JM, Aksnes DL, Thompson EM (2002) Resource allocation between somatic growth and reproductive output in the pelagic chordate Oikopleura dioica allows opportunistic response to nutritional variation. Mar Ecol Prog Ser 243:83-91 doi:10.3354/meps243083

Tsuda A, Nemoto T (1992) Distribution and growth of salps in a Kuroshio warm-core ring during summer 1987. Deep-Sea Res 39:S219-S229 doi:10.1016/S0198-0149(11)80013-0

Ulses C, Estournel C, Puig P, Durrieu de Madron X, Marsaleix P (2008) Dense shelf water cascading in the northwestern Mediterranean during the cold winter 2005: quantification of the export through the Gulf of Lion and the Catalan margin. Geophys Res Lett 35:L07610 doi:10.1029/2008GL033257

Venrick EL, Hayward TL (1984) Determining chlorophyll on the 1984 CALCOFI surveys. Calif Coop Ocean Fish Invest Rep 25:74-79

Wiebe PH, Madin LP, Haury LR, Harbison GR, Philbin LM (1979) Diel vertical migration by Salpa aspera and its potential for large-scale particulate organic matter transport to the deep-sea. Mar Biol 53:249-255 doi:10.1007/BF00952433 


\section{FIGURES AND TABLES}

Fig. 1. Life cycle flows of the salp Thalia democratica under (a) high and (b) low temperature following the selected model. Life stages are indicated by $\mathrm{F}$ (females), $\mathrm{M}$ (males), $\mathrm{J}$ (juvenile oozooids) and PO (productive oozooids). $P_{\mathrm{F}}, P_{\mathrm{M}}, P_{\mathrm{J}}$ and $P_{\mathrm{PO}}$ are probabilities of remaining in the corresponding stage, and $G_{\mathrm{F}}$ and $G_{\mathrm{J}}$ are the probabilities of becoming male and productive oozooid, respectively. Dashed lines indicate reproductive flows $\left(R_{\mathrm{J}}, R_{\mathrm{PO}}\right.$ and $\left.R_{\mathrm{F}}\right)$; light grey arrows show constant fluxes; thick and thin dark grey arrows indicate fluxes that increase and decrease in each scenario, respectively

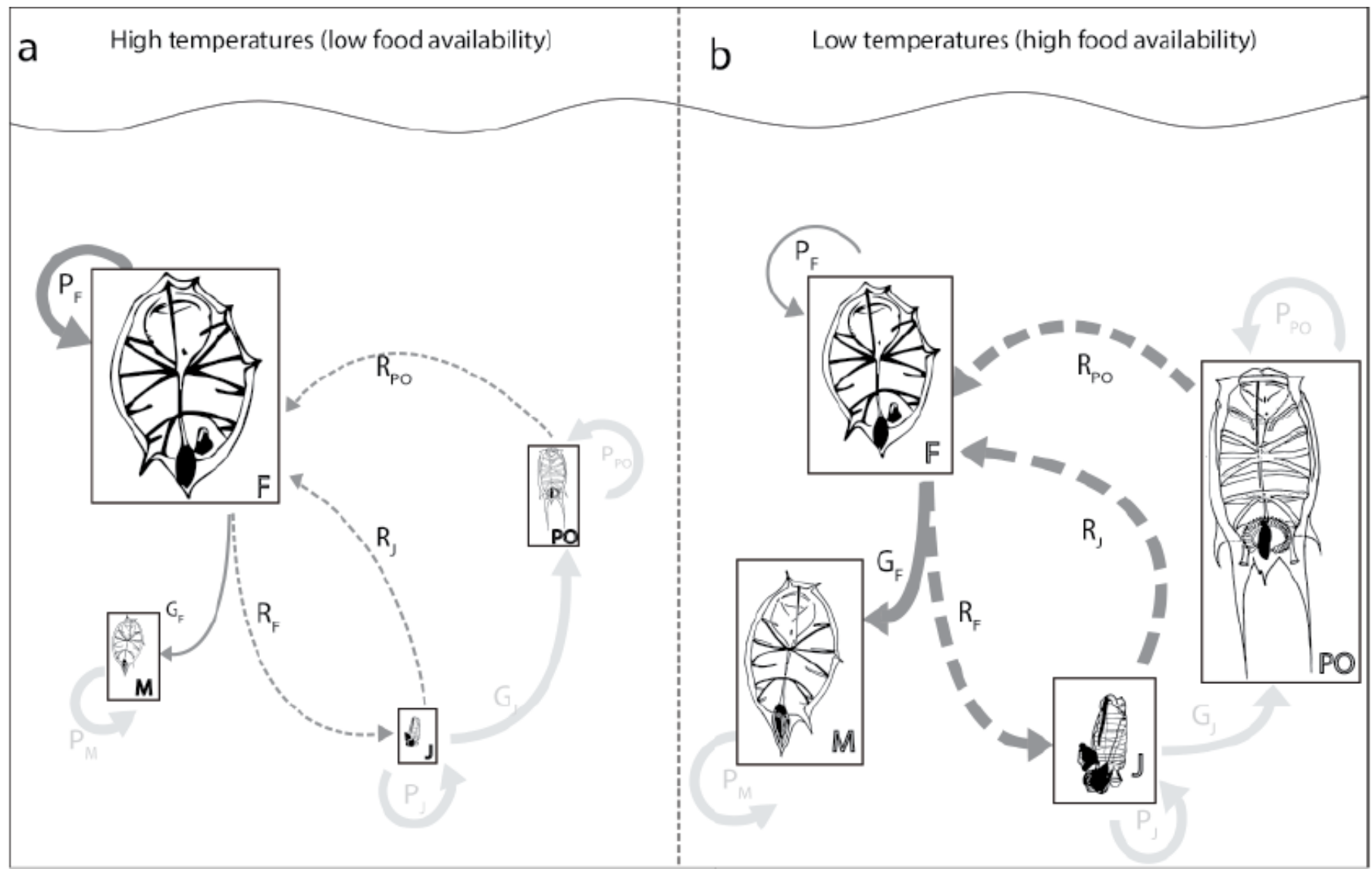


Fig. 2. Study locations in Spain: Cadaqués, located in front of the Cap de Creus area $\left(42^{\circ} 18.575^{\prime}\right.$ $\left.\mathrm{N}, 3^{\circ} 19.321^{\prime} \mathrm{E}\right)$ and Barcelona, on the central coast $\left(41^{\circ} 20.844^{\prime} \mathrm{N}, 2^{\circ} 17.888^{\prime} \mathrm{E}\right)$

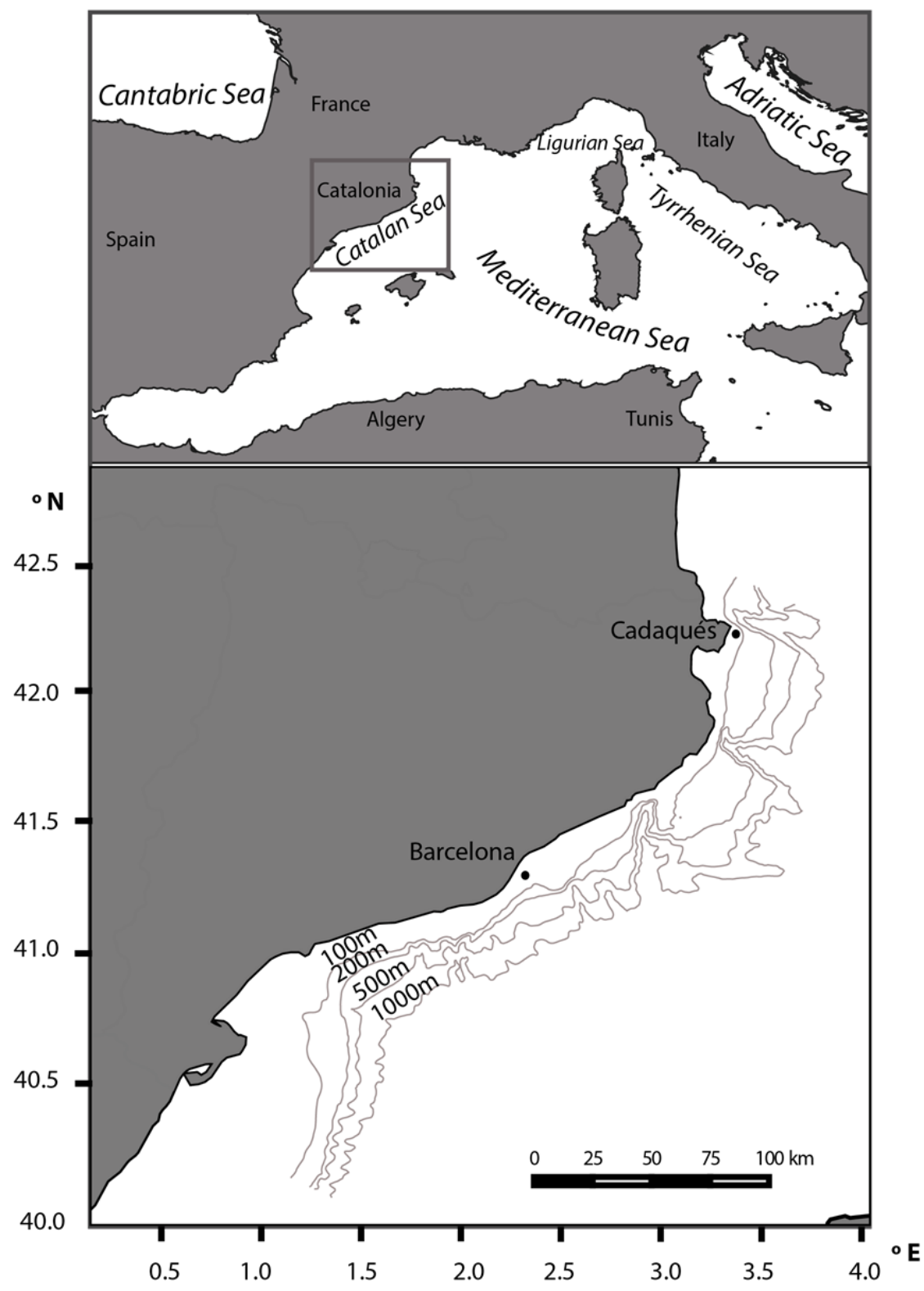


Fig. 3. Temporal evolution during 2013 and 2014 of environmental parameters and salp Thalia democratica populations in Cadaqués and Barcelona. Solid and dashed lines indicate temperature and total chlorophyll, respectively; vertical bars show $T$. democratica densities (open bars indicate densities <1 ind. $100 \mathrm{~m}^{-3}$ ). *: short time-series studies, where only the first measurement is represented; sf: surveys in which Salpa fusiformis were found. Discontinuities in total chlorophyll and temperature lines are due to missing values

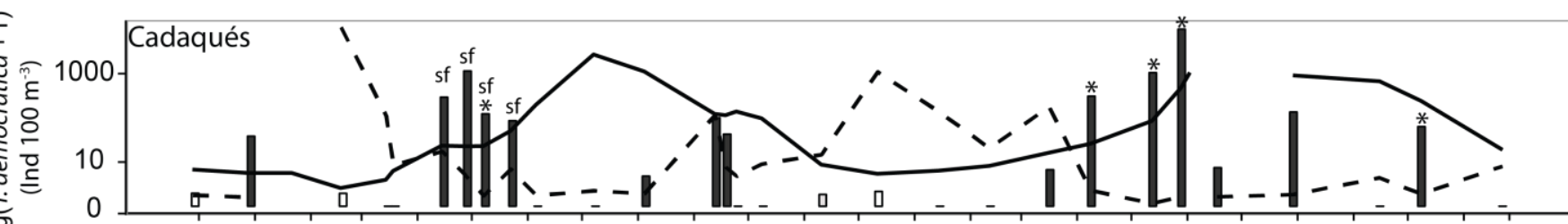

Barcelona

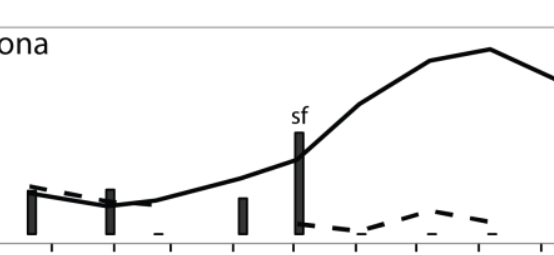

Jan Feb Mar Apr May Jn I Aug Sep Oct Nov Dec Jan Feb Mar Apr May Jn I Aug Sep Oct Nov Dec 
Fig. 4. (a) Female salp Thalia democratica matrix parameters under different temperatures resulting from the best model selected. $P_{\mathrm{F}}$ : probability of remaining in the female stage, $G_{\mathrm{F}}$ : probability of growing to the male stage, $R_{\mathrm{F}}$, probability of giving birth. (b) Population growth $(\lambda)$ and elasticity with respect to each matrix parameter under different temperatures. Matrix parameters $(P, G, R)$ are explained in the Materials and Methods, and see Fig. 1 for definitions of abbreviations. Brown bars on the $x$-axis indicate temperatures from the samples used to fit the model

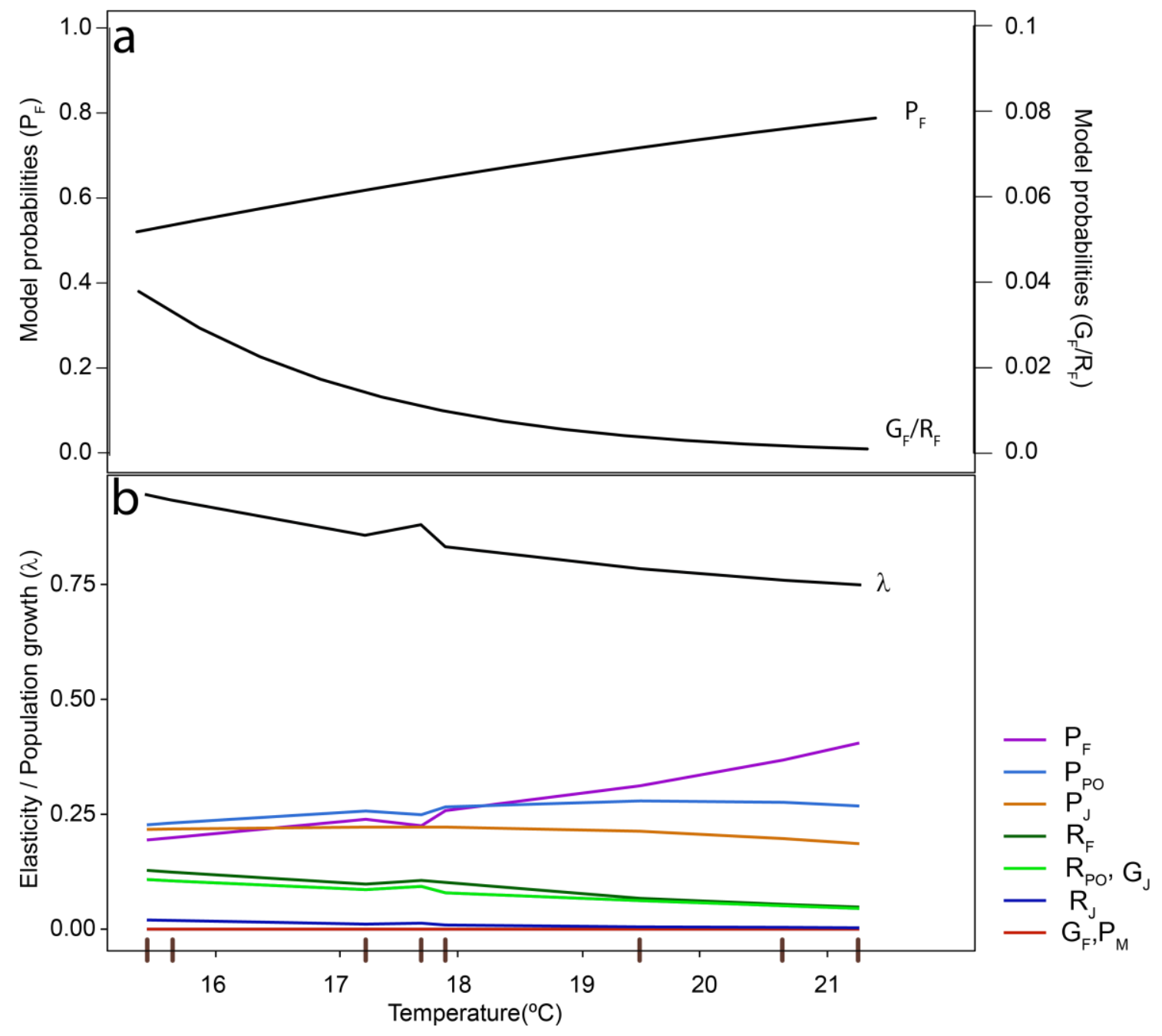


Fig. 5. Observed densities of salp Thalia democratica at time $t+1$ (black dashed line) and their 1-time-step expected densities given the observed densities at previous time $t$ corresponding to the selected model (blue triangles). Longest segments of each triangle define maximum and minimum confidence intervals for each 1-time-step expected densities. Columns indicate the different life stages (F: female, M: male, J: juvenile, PO: productive oozooid); rows correspond to each sampling day; dates are given as $\mathrm{dd} / \mathrm{mm} / \mathrm{yyyy}$
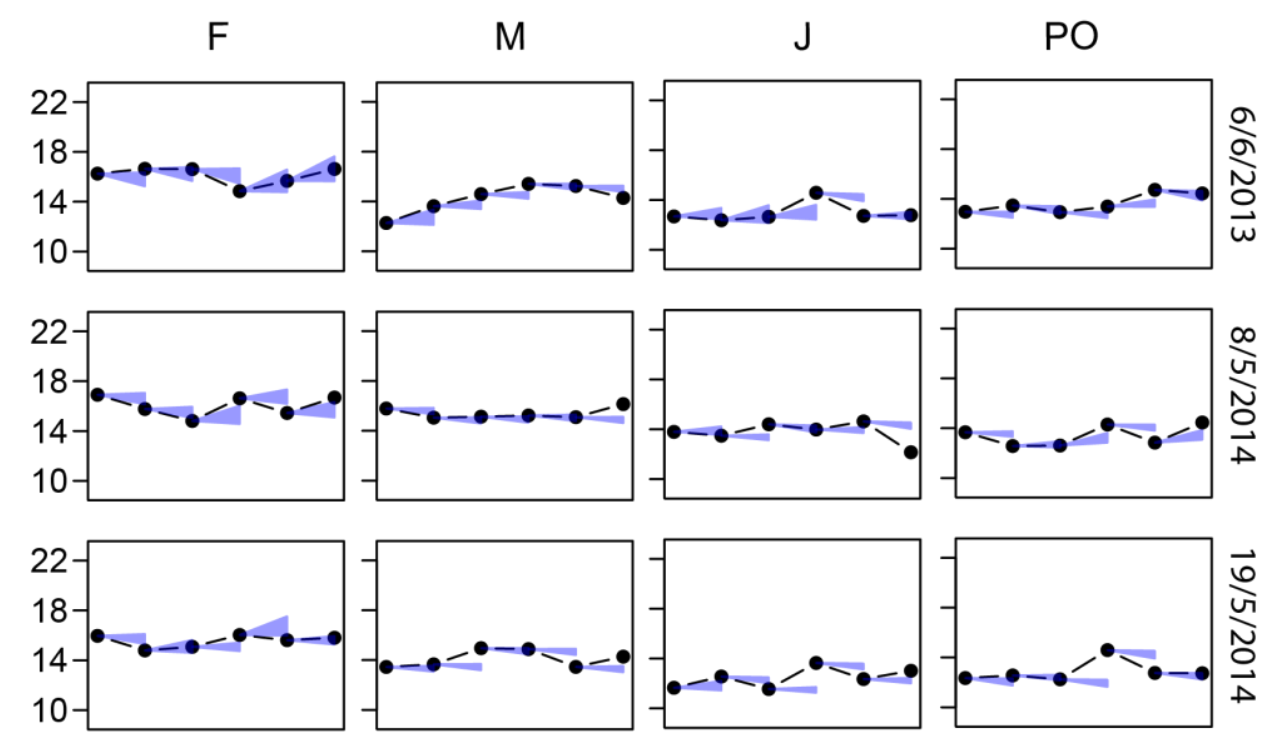

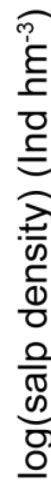
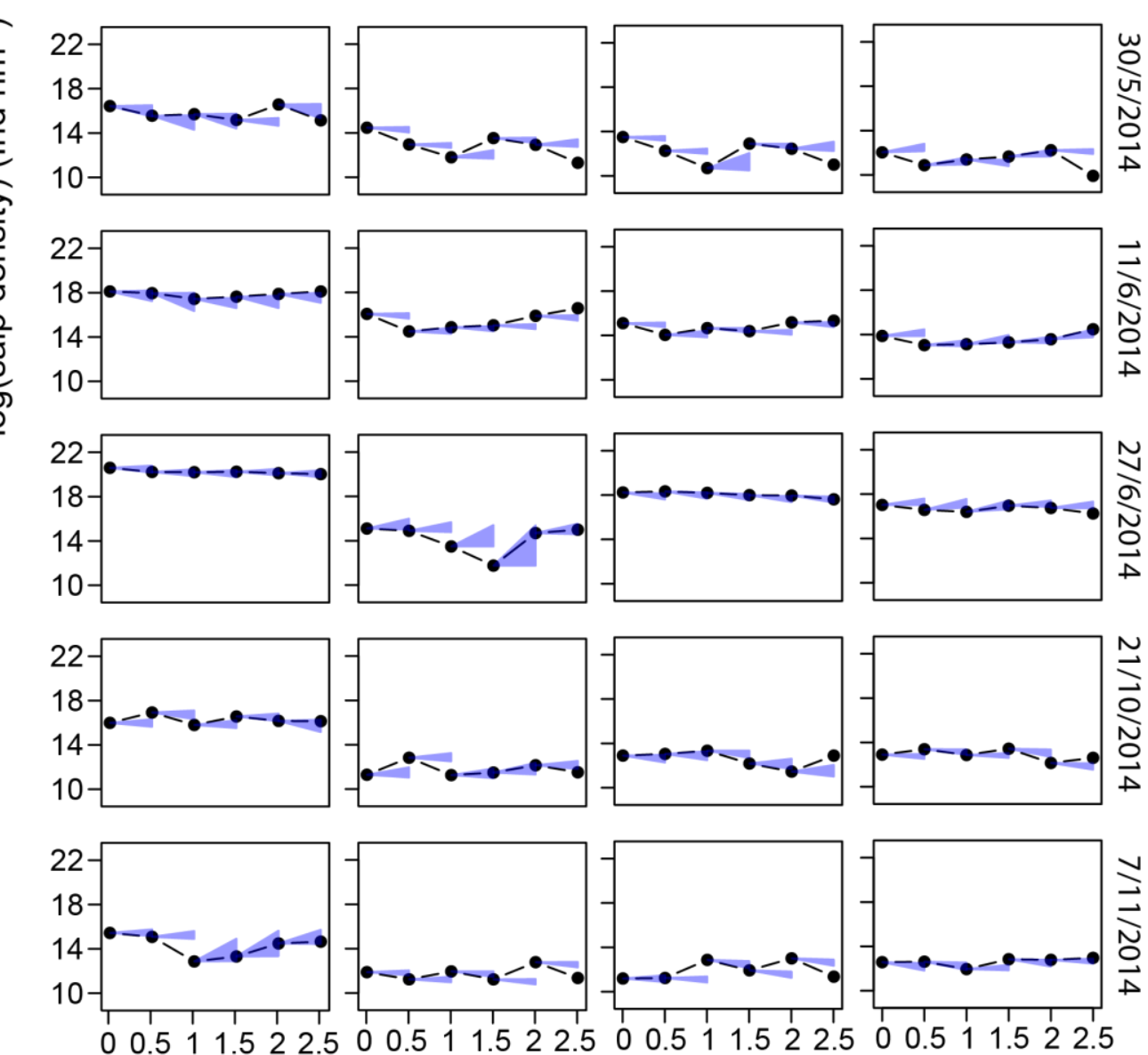

time (hours) 
Table 1. Dependence of matrix elements (cf. Eq. 1) on temperature (T) and chlorophyll concentration $(c h l)$ by means of binomial or multinomial functions. $f$ : fecundity or number of blastozooids of salp Thalia democratica produced by an oozooid; $S_{0}$ : is the survival of the newborn blastozooids until the start of the next time interval. Note that $\alpha, \beta, \delta, \gamma, \varepsilon, f_{\min }$ and $f_{\max }$ are model parameters. Transition matrix elements are explained in Fig. 1

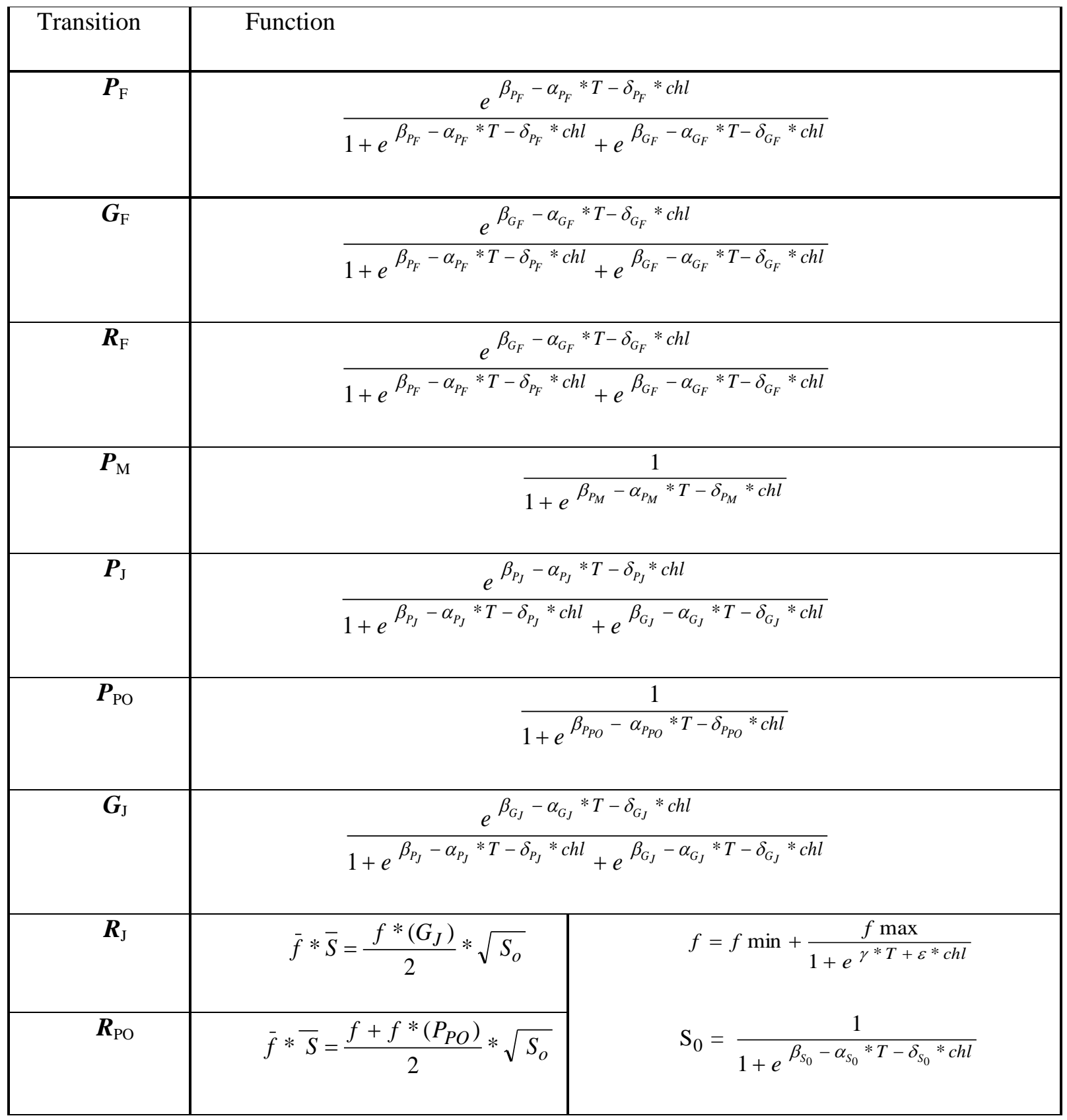


Table 2. Summary of the model selection results. Digits in the first 4 columns indicate whether transitions out of the female (F), male (M), juvenile (J) and productive oozooid (PO) stages of salp Thalia democratica have (1) or have not (0) been modelled with chlorophyll and/or temperature effects. The following 9 columns report the residuals of the cross-validation method $(\mathrm{Cv})$, of the non-linear least squares optimization $(\mathrm{Opt})$ and the total number of parameters to optimize $(\Theta)$ for models including temperature, chlorophyll and both. The selected model is highlighted in bold

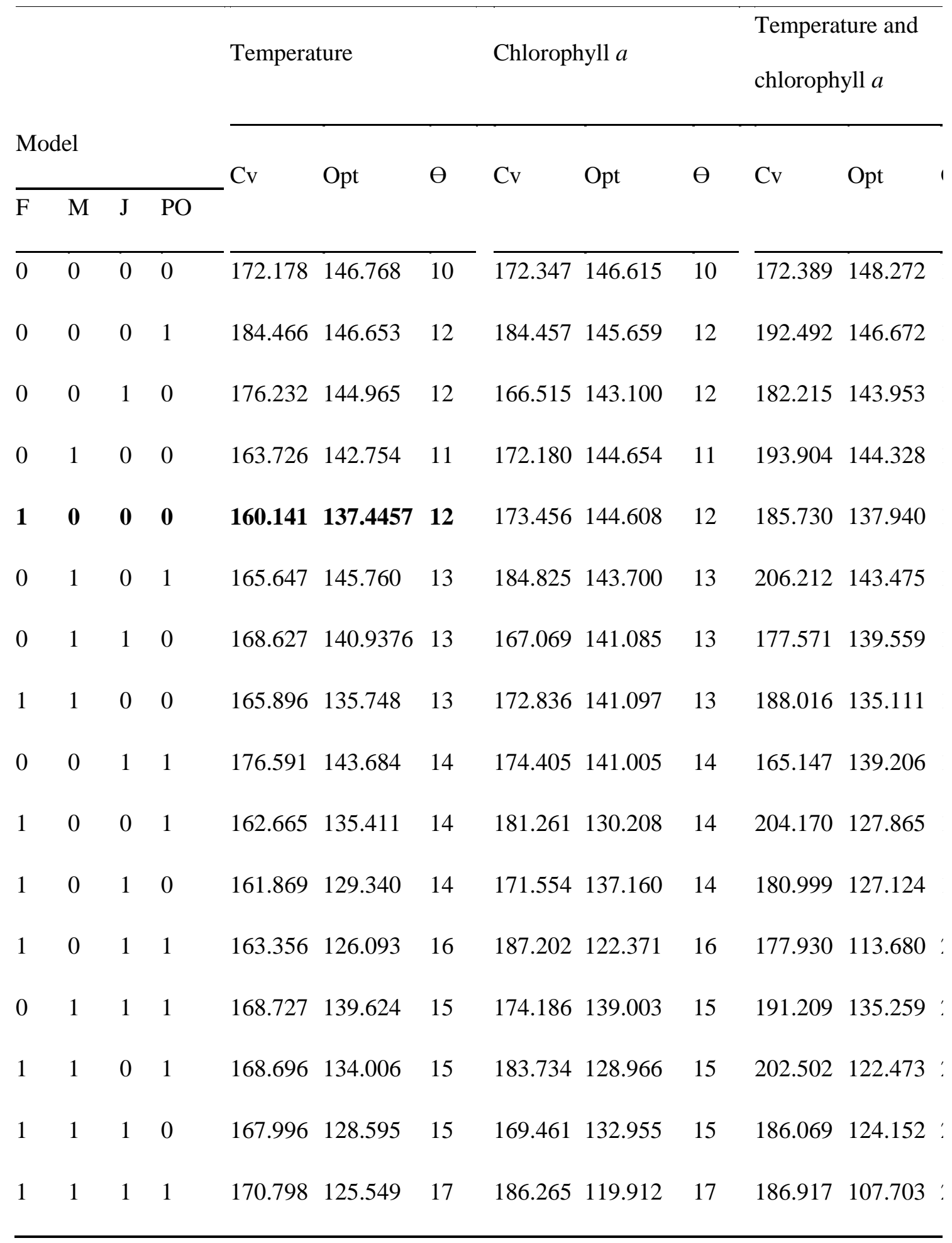


Table 3. Matrix elements and their corresponding functions or fixed values resulting from the best model, i.e. the one with the lowest cross-validation error $(\mathrm{Cv})$ in Table 2. $f$ : fecundity term; $\mathrm{S}_{0}$ : survival. See Fig. 1 for other definitions

\begin{tabular}{|l|l|}
\hline Matrix element & Function or fixed value \\
\hline$P_{\mathrm{F}}$ & $\mathrm{e}^{-2.809+0.193 \times T} /\left(1+\mathrm{e}^{-2.803+0.193 \times T}+\mathrm{e}^{3.945-0.415 \times T}\right)$ \\
\hline$G_{\mathrm{F}} / R_{\mathrm{F}}$ & $\mathrm{e}^{3.945-0.415 \times T} /\left(1+\mathrm{e}^{-2.803+0.193 \times T}+\mathrm{e}^{3.945-0.415 \times T}\right)$ \\
\hline$P_{\mathrm{M}}$ & 0.739 \\
\hline$R_{\mathrm{J}}$ & $0.011 \times f$ \\
\hline$G_{\mathrm{J}}$ & 0.204 \\
\hline$P_{\mathrm{J}}$ & 0.615 \\
\hline$R_{\mathrm{PO}}$ & $0.009 \times f$ \\
\hline$P_{\mathrm{PO}}$ & 0.639 \\
\hline$f$ & $14.001+222.26 /\left(1+\mathrm{e}^{0.112 \times T}\right)$ \\
\hline$S_{0}$ & $1 /\left(1+\mathrm{e}^{4.518}\right)=0.011$ \\
\hline
\end{tabular}

Table 4. Model stage-dependent survival of salp Thalia democratica calculated from our model $P$ and $G$ probabilities (see Fig. 1) and compared to survival derived from the model of Henschke et al. (2015) assuming their daily survivals were constant

\begin{tabular}{|lll|}
\hline Stage & $\begin{array}{l}\text { Survival } \\
\text { (this study) }\end{array}$ & $\begin{array}{l}\text { Survival } \\
\text { (Henschke et al. 2015) }\end{array}$ \\
\hline Female (F) & $0.51-0.81$ & 0.84 \\
Male (M) & 0.739 & 0.55 \\
Juvenile (J) & 0.813 & 0.89 \\
Productive oozooid (PO) & 0.639 & 0.55 \\
\hline
\end{tabular}




\section{SUPPLEMENTARY MATERIAL}

Figure S1. Length frequencies of the 10 surveys (a, b, c, d, e, f, g, h, i, j) expressed as logarithm of the counts for blastozooids (left column) and oozooids (right column). Each row portraits a time series sample, half an hour apart from the previous one. Grey bars indicate young stages (females and juvenile oozooids) and black bars indicate mature stages (males and productive oozooids). Environmental conditions (temperature and chlorophyll $a$ concentration), date and location are given for each survey. Note that surveys $\mathrm{d}$ and $\mathrm{h}$ were not used to fit the model since they have only five time transitions. 
a Survey date: $06 / 06 / 2013$ Temperature: $15.43^{\circ} \mathrm{C}$ Chlorophyll -a: $0.124 \mathrm{mg} \mathrm{m}^{-3}$ Location: Cadaqués

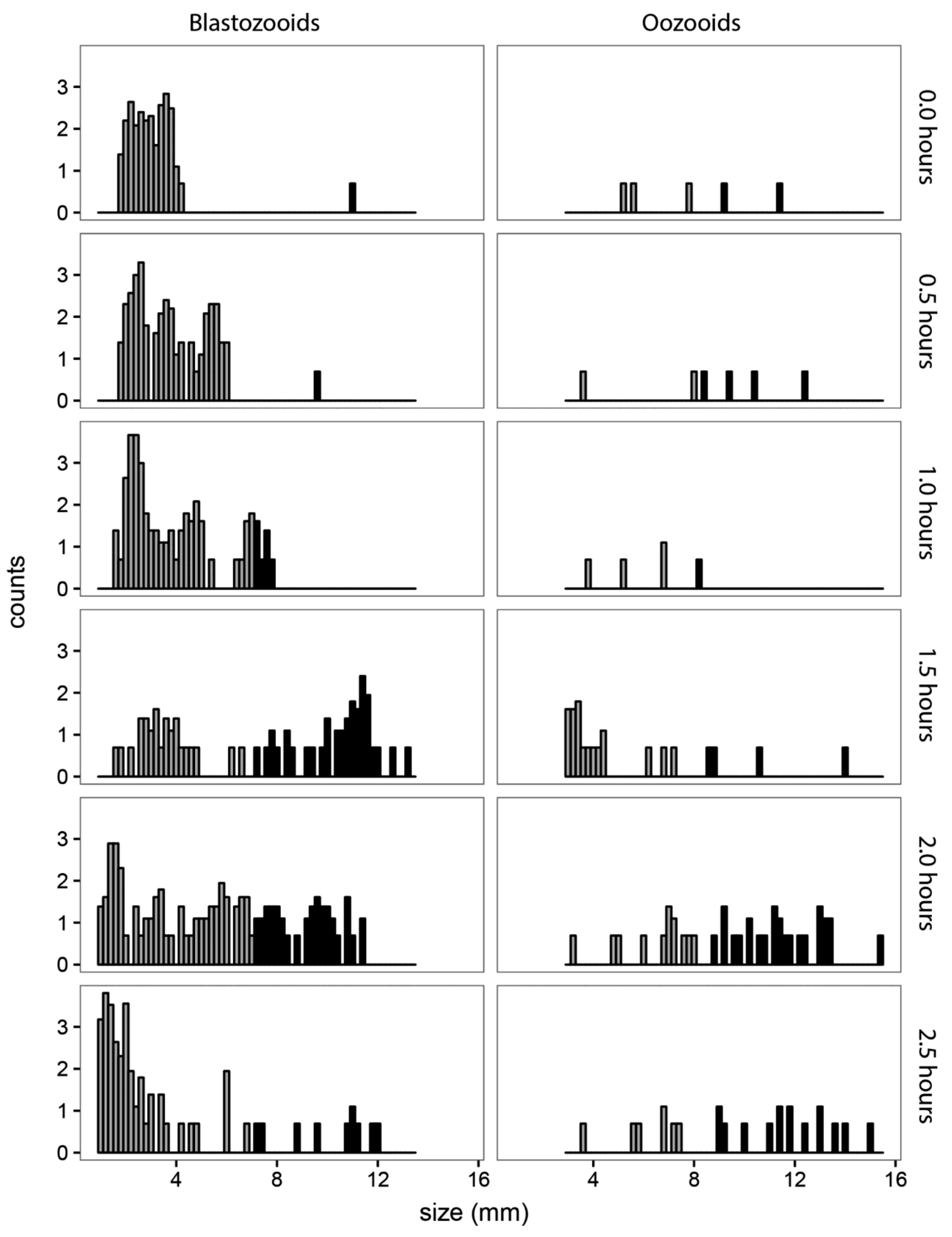


b Survey day: 08 / $05 / 2014$ Temperature: $15.64{ }^{\circ} \mathrm{C}$ Chlorophyll-a: $0.160 \mathrm{mg} \mathrm{m}^{-3}$ Location: Cadaqués
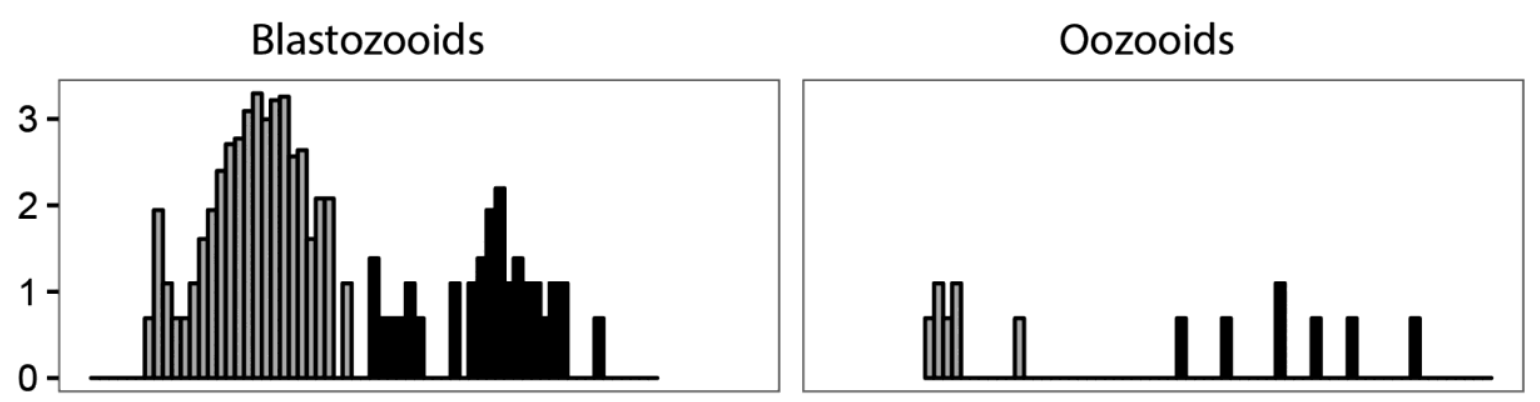

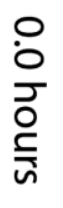
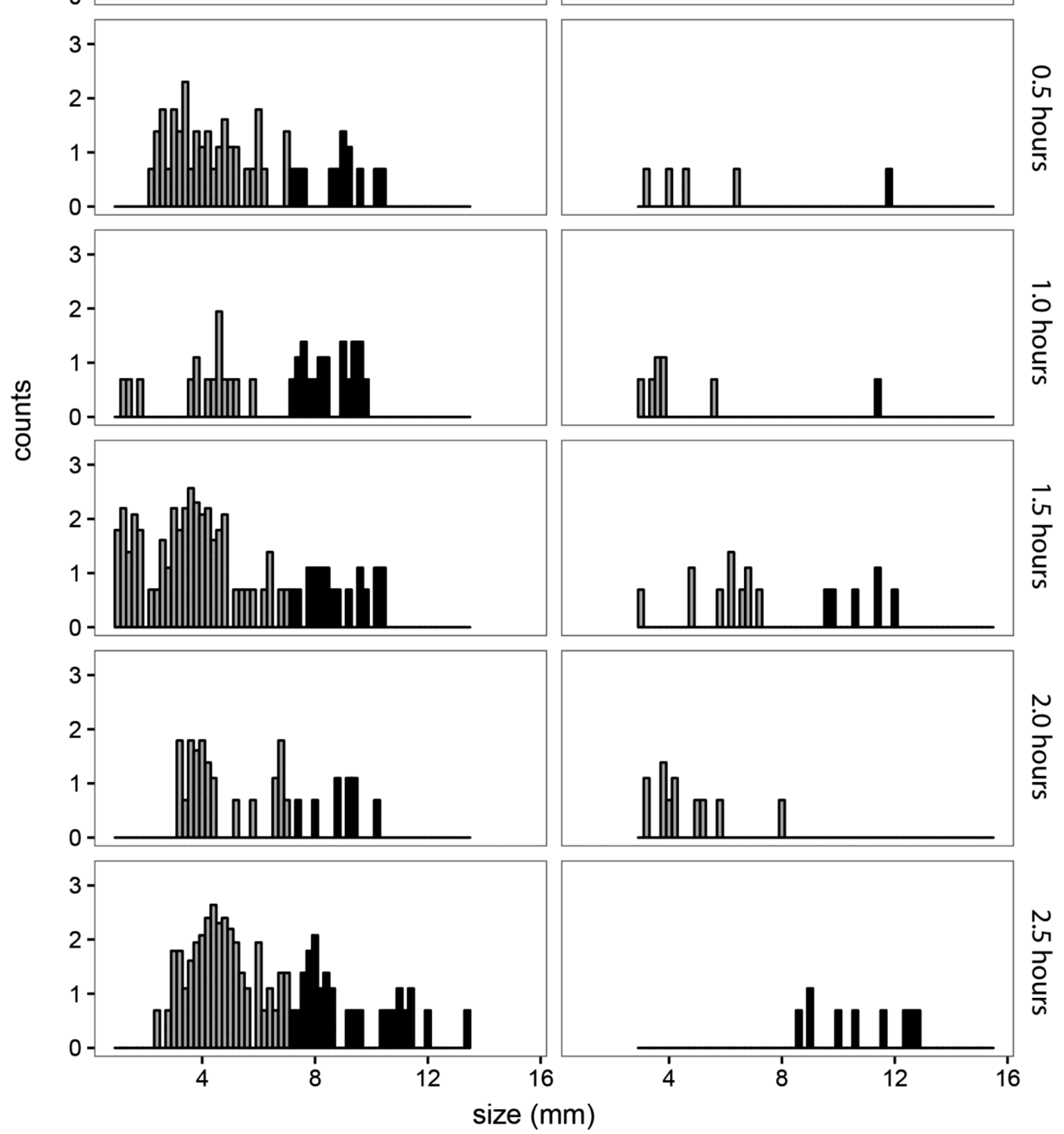

$n$
in
$\frac{0}{5}$
$\frac{\mathrm{n}}{n}$ 
C Survey day: $19 / 05 / 2014$ Temperature: $17.9{ }^{\circ} \mathrm{C}$ Chlorophyll -a: $0.139 \mathrm{mg} \mathrm{m}^{-3}$ Location: Barcelona

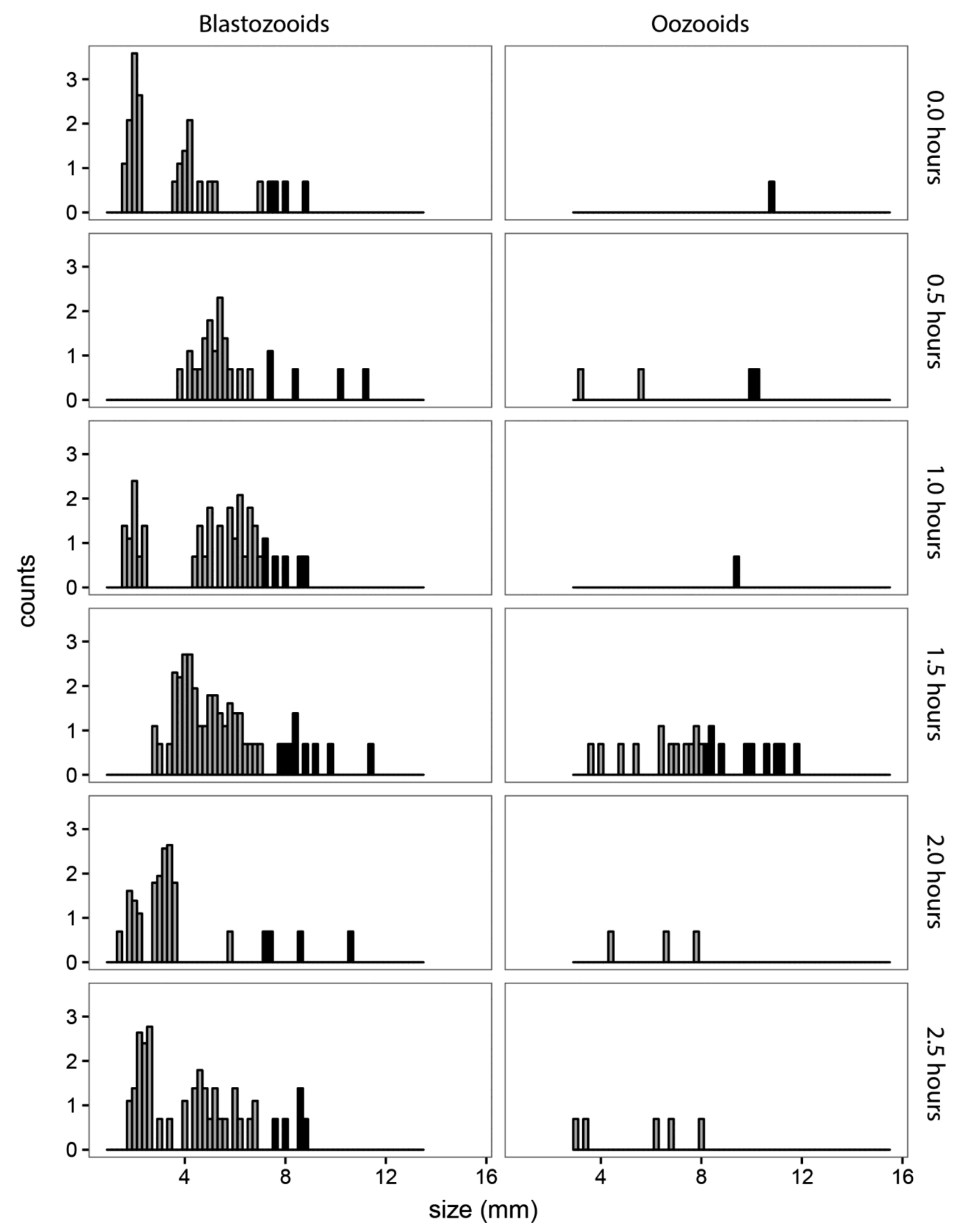


d Survey day: $27 / 05 / 2014$ Temperature: $17.13^{\circ} \mathrm{C}$ Chlorophyll -a: $0.258 \mathrm{mg} \mathrm{m}^{-3}$ Location: Barcelona

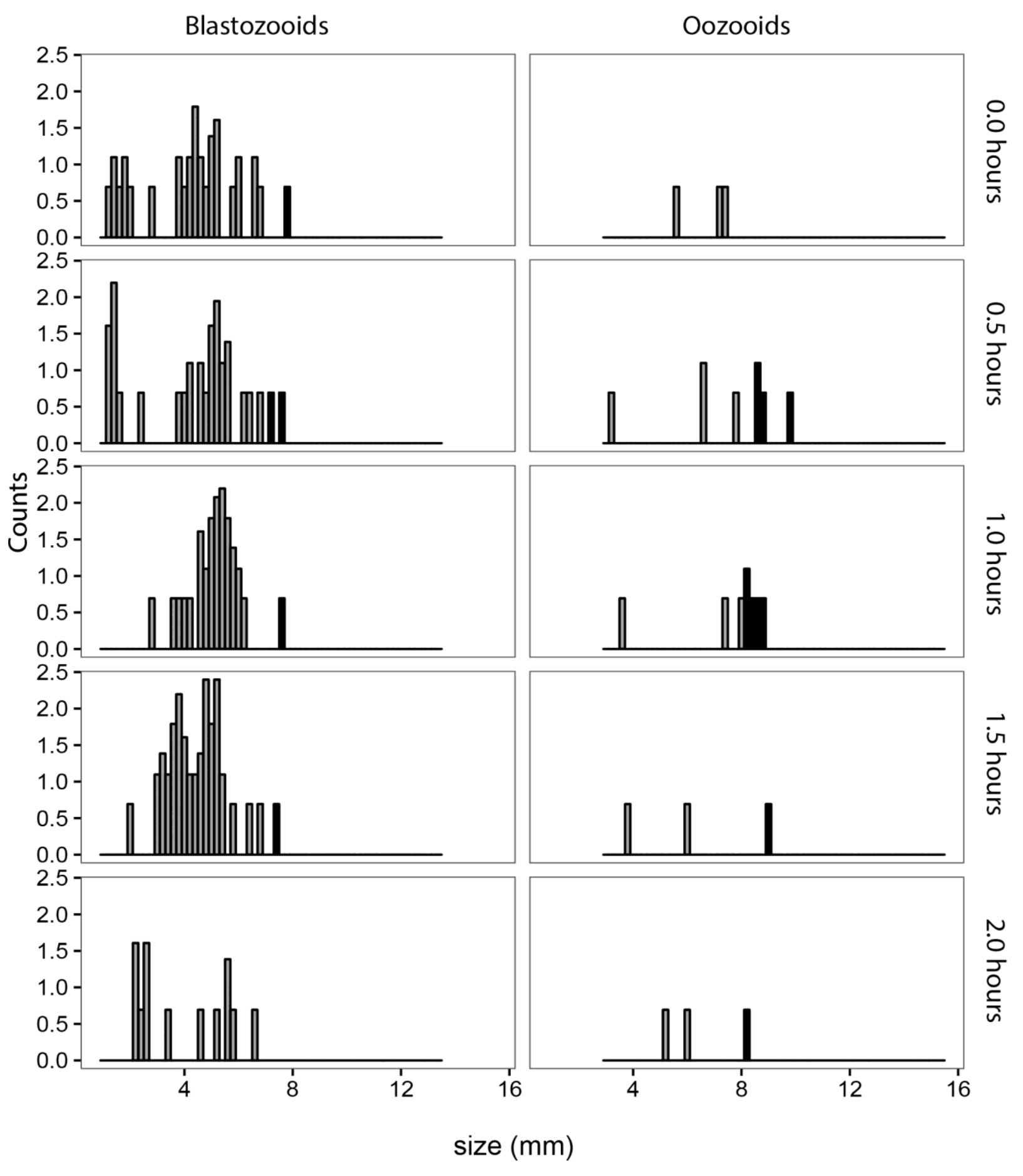


e Survey day: $30 / 05 / 2014$ Temperature: $17.24^{\circ} \mathrm{C}$ Chlorophyll -a: $0.177 \mathrm{mg} \mathrm{m}^{-3}$ Location: Barcelona

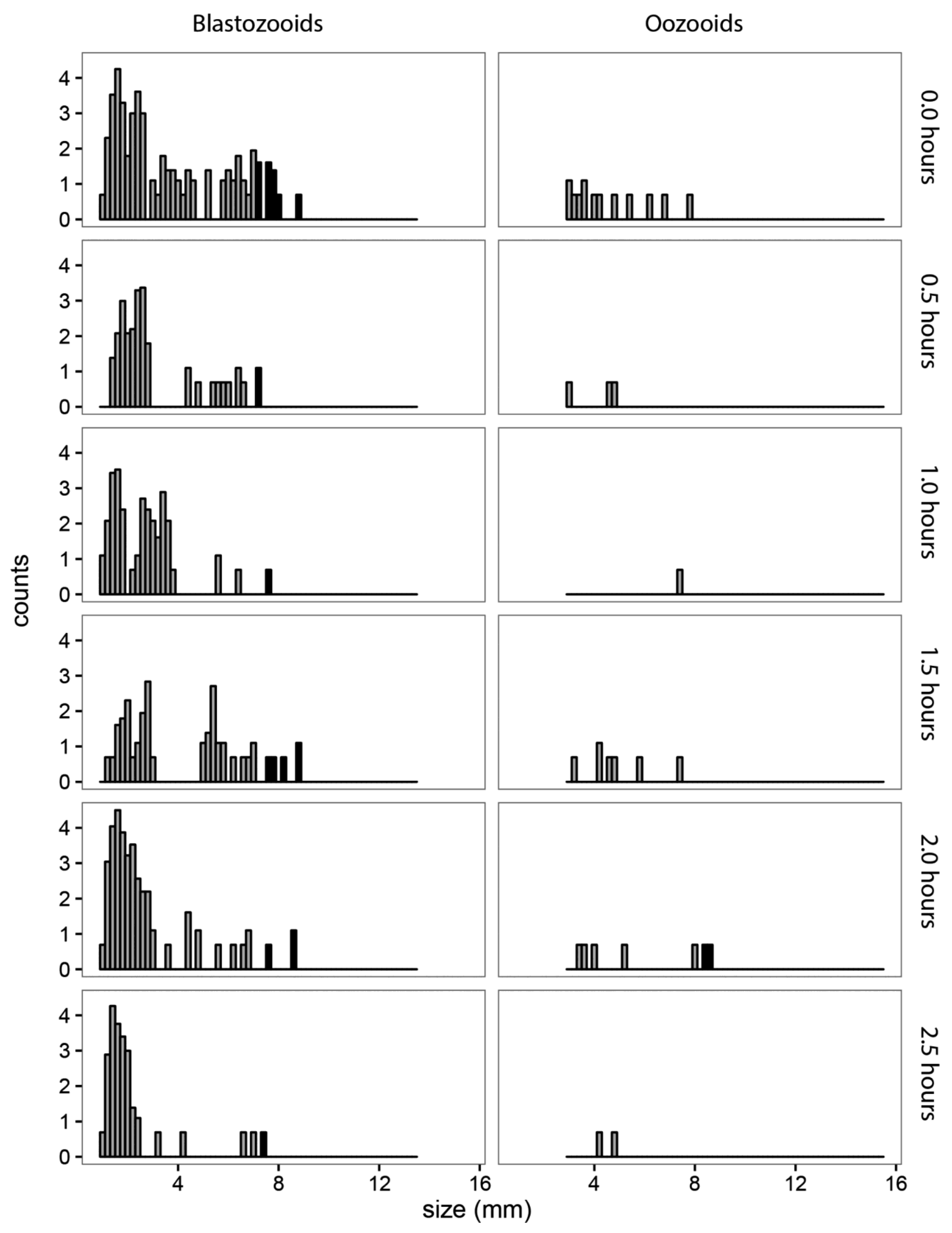


f Survey day: $11 / 06 / 2014$ Temperature: $17.71{ }^{\circ} \mathrm{C}$ Chlorophyll-a: $0.073 \mathrm{mg} \mathrm{m}^{-3}$ Location: Cadaqués

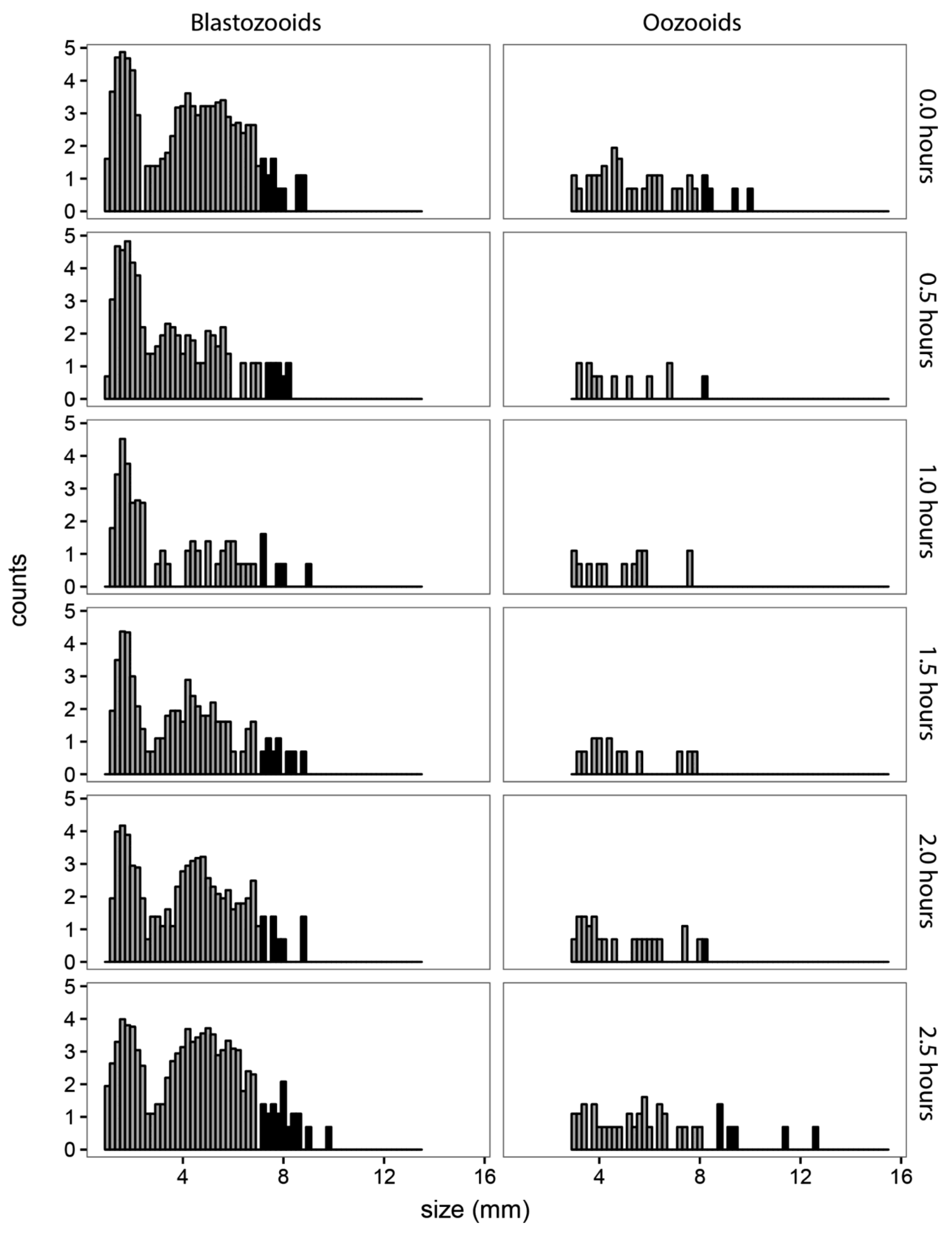


9 Survey day: $27 / 06 / 2014$ Temperature: $20.69{ }^{\circ} \mathrm{C}$ Chlorophyll-a: $0.119 \mathrm{mg} \mathrm{m}^{-3}$ Location: Cadaqués

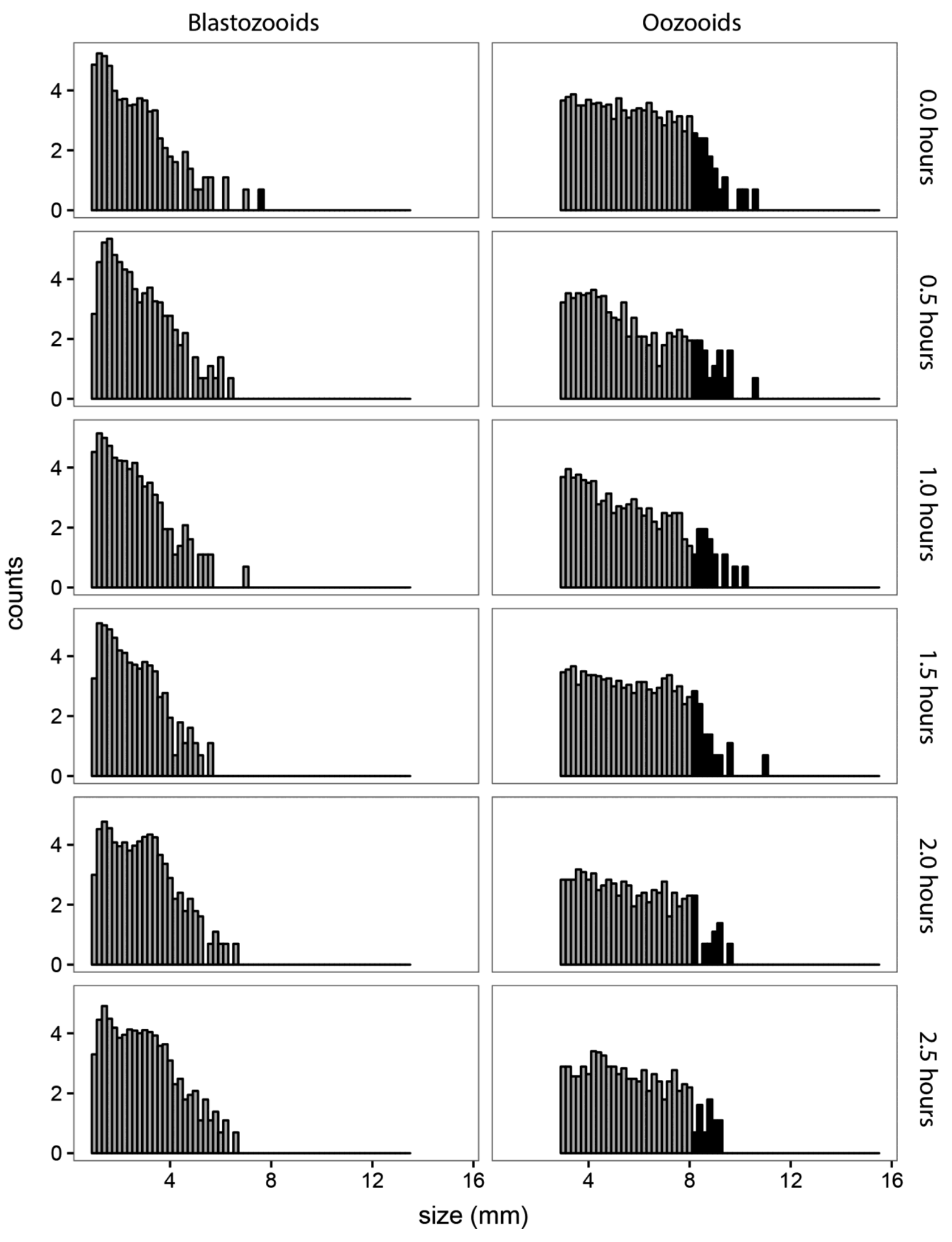


h Survey day: $16 / 10 / 2014$ Temperature: $21^{\circ} \mathrm{C}$ Chlorophyll -a: $0.137 \mathrm{mg} \mathrm{m}^{-3}$ Location: Cadaqués

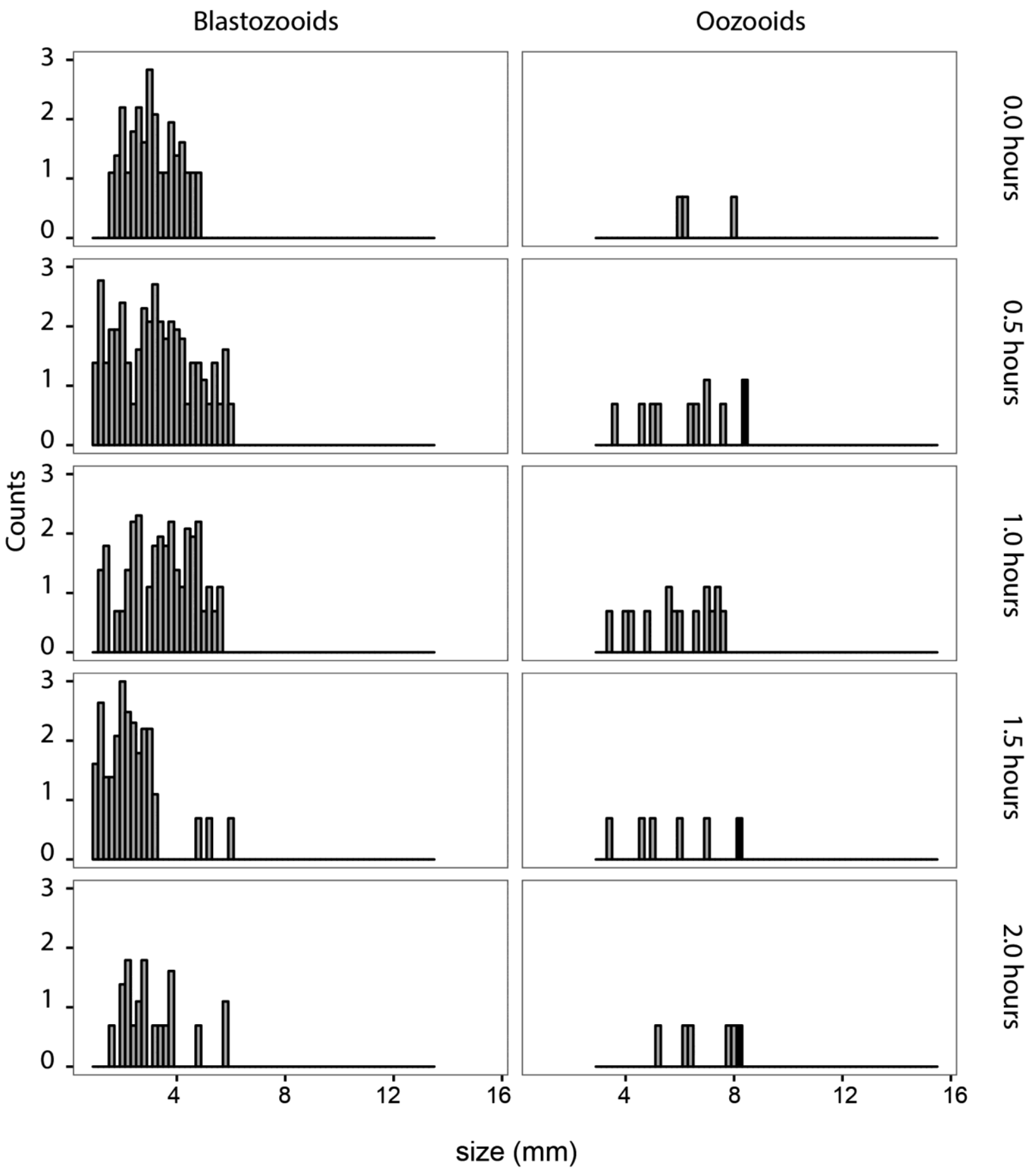


Survey day: $21 / 10 / 2014$ Temperature: $21.32^{\circ} \mathrm{C}$ Chlorophyll -a: $0.104 \mathrm{mg} \mathrm{m}^{-3}$ Location: Barcelona

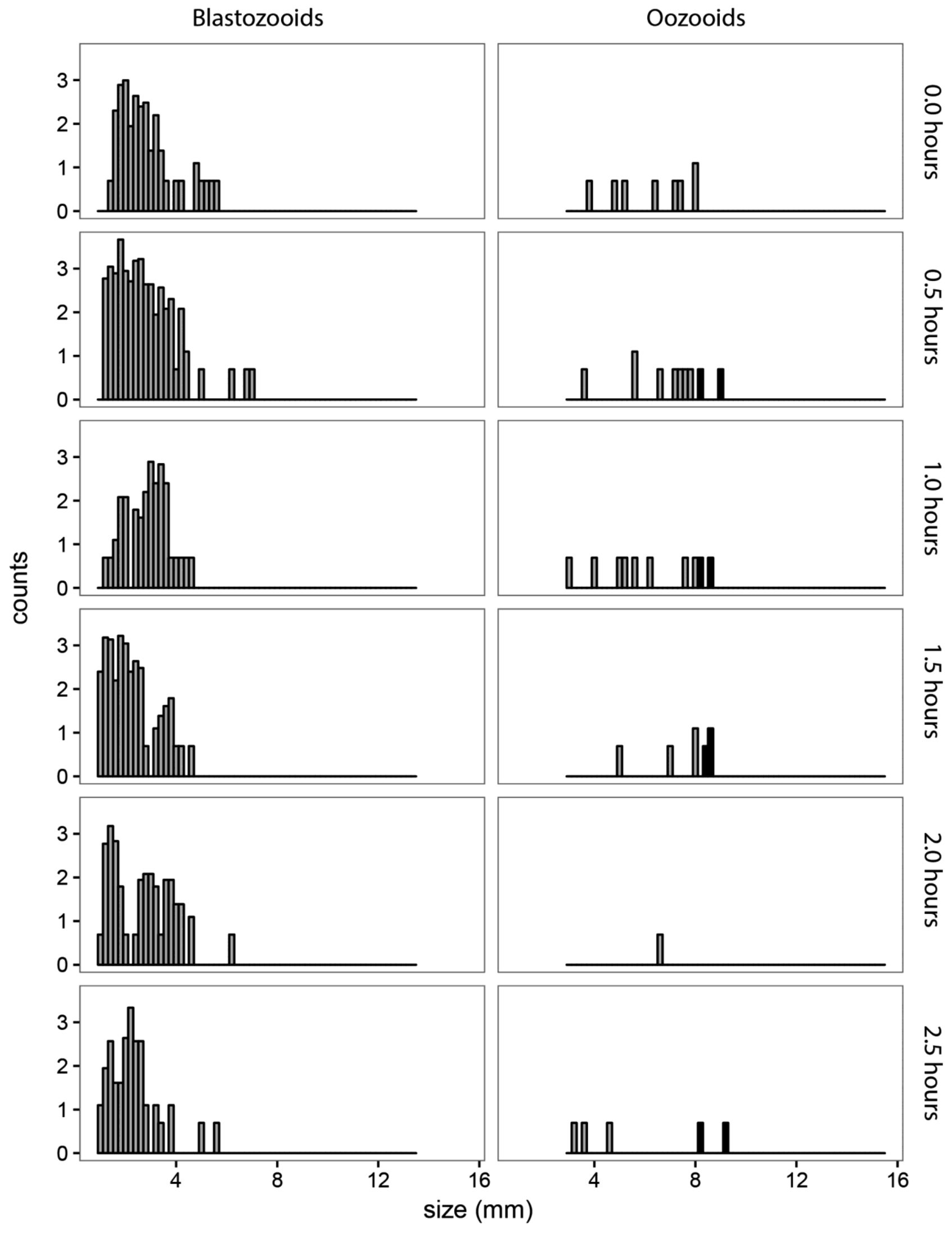




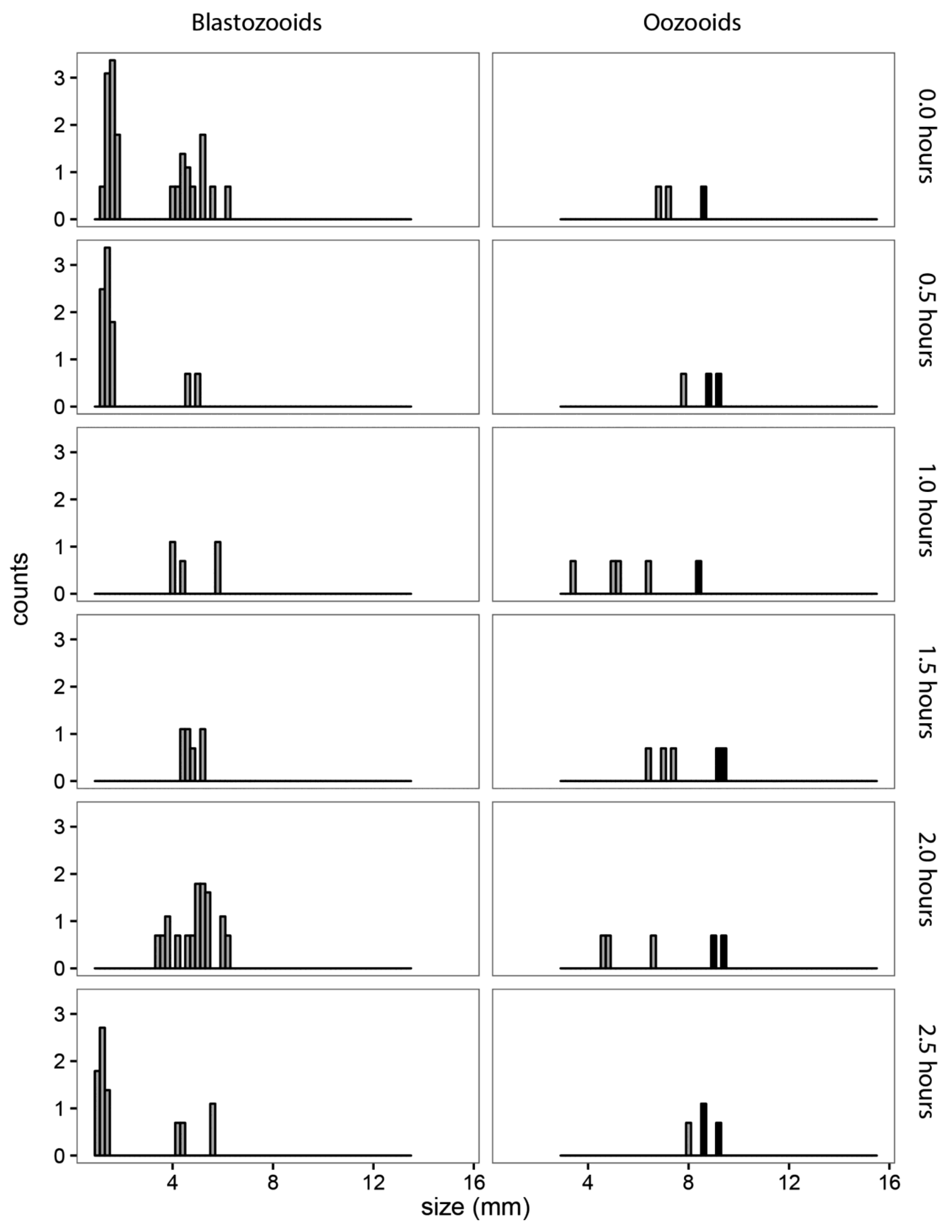

